\title{
Spatial and Temporal Variability of Antarctic Precipitation from Atmospheric Methods*
}

\author{
Richard I. Cullather AND David H. Bromwich ${ }^{+}$ \\ Polar Meteorology Group, Byrd Polar Research Center, Ohio State University, Columbus, Ohio \\ Michael L. VAN WOERT \\ Office of Research and Applications, NOAA/NESDIS, Camp Springs, Maryland
}

(Manuscript received 9 January 1997, in final form 23 June 1997)

\begin{abstract}
The spatial and temporal variability of net precipitation (precipitation minus evaporation/sublimation) for Antarctica derived from the European Centre for Medium-Range Weather Forecasts operational analyses via the atmospheric moisture budget is assessed in comparison to a variety of glaciological and meteorological observations and datasets. For the 11-yr period 1985-95, the average continental value is $151 \mathrm{~mm} \mathrm{yr}^{-1}$ water equivalent. Large regional differences with other datasets are identified, and the sources of error are considered. Interannual variability in the Southern Ocean storm tracks is found to be an important mechanism for enhanced precipitation minus evaporation $(P-E)$ in both east and west Antarctica. In relation to the present findings, an evaluation of the rawinsonde method for estimating net precipitation in east Antarctica is conducted. Estimates of $P-E$ using synthetic rawinsondes derived from the analyses are found to compare favorably to glaciological estimates. A significant upward trend of $2.4 \mathrm{~mm} \mathrm{yr}^{-1}$ is found for the Antarctic continent that is consistent with findings from the National Centers for Environmental Prediction, formerly the National Meteorological Center, and the National Center for Atmospheric Research Reanalysis precipitation dataset. Despite large regional discrepancies, the general agreement on the main features of Antarctic precipitation between studies suggests that a threshold has been reached, where the assessment of the smaller terms including evaporation/sublimation and drift snow loss is required to explain the differences.
\end{abstract}

\section{Introduction}

Precipitation over Antarctica is recognized as an important climatic variable (Bromwich 1990). The rate of accumulation of snow and ice is necessary information for the assessment of the stability and motion of the Antarctic ice sheets, which in turn play an important role in the global sea level budget. The annual precipitation over the ice sheets may be thought of in terms of equivalent sea level decrease, which has been estimated to be large $\left(\sim 8 \mathrm{~mm} \mathrm{yr}^{-1}\right)$ in relation to current estimations of global sea level rise ( $\sim 1$ to $3 \mathrm{~mm} \mathrm{yr}^{-1}$ ) (Warrick et al. 1995). The eustatic impact of the ice sheets arises because precipitation may vary rapidly over time, while the ice-sheet response occurs over

\footnotetext{
* Byrd Polar Research Center Contribution Number 1057.

+ Current affiliation: Atmospheric Sciences Program, Ohio State University, Columbus, Ohio.
}

Corresponding author address: David H. Bromwich, Polar Meteorology Group, Byrd Polar Research Center, Ohio State University, Columbus, OH 43210-1002.

E-mail: bromwich@polarmet1.mps.ohio-state.edu much longer timescales (Fortuin and Oerlemans 1990). Additionally, precipitation in polar regions has been forecast to increase with potential increases in global temperature (Kattenberg et al. 1995); hence, the monitoring of the cryosphere is an important component of detecting global change.

Difficulties in obtaining accurate estimates of Antarctic precipitation have been documented (Bromwich 1988). Direct in situ gauge measurements are complicated by wind biases and the presence of an unlimited snow field. The introduction of blowing snow creates the problem of distinguishing snow that has been precipitated from that which has been picked up by the wind and transported. Additionally, over the interior Antarctic plateau, snowfall amounts are less than the minimum gauge resolution. Attempts to correct gauge values for wind bias have been made on a global basis (e.g., Legates and Willmott 1990). The quality of the corrected precipitation depictions for the Antarctic has not been assessed, however.

In contrast to gauge measurements, accumulation estimates derived from glaciological methods are generally straightforward and considered reliable, due in part to the variety of methods available which may then be 


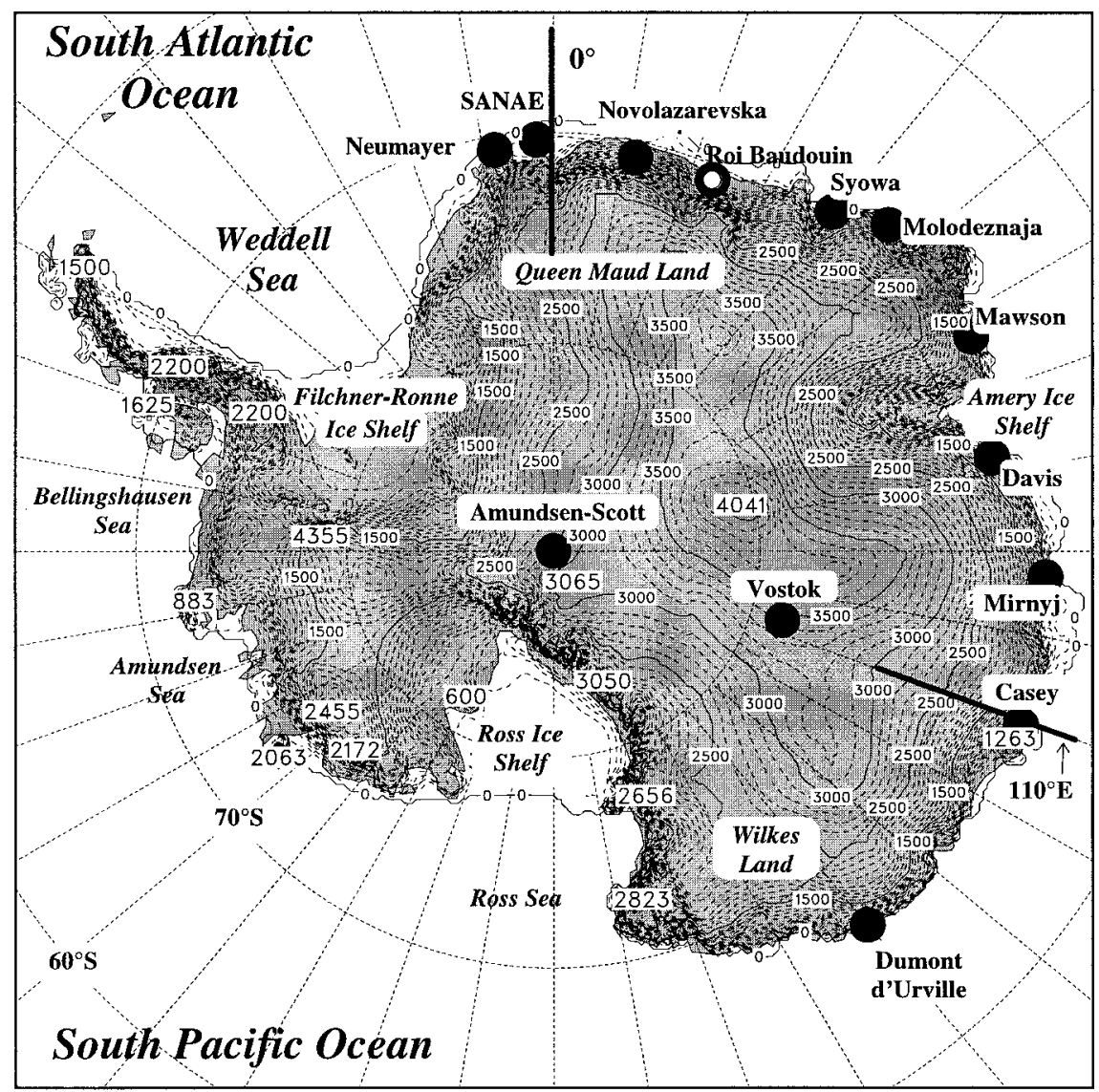

FIG. 1. Antarctic continent showing rawinsonde stations in east Antarctica (filled circles), Roi Baudoin Station (not operational since the 1960s, open circle) and contours of the Drewry (1983) elevation dataset.

intercompared (Schwerdtfeger 1984). The disadvantage here is the lack of an adequate and uniform temporal resolution for large areas of the continent. As a result, only the long-term synthesized depictions of the spatial variability in accumulation are presently available (Giovinetto and Bentley 1985; Giovinetto and Bull 1987), with the interannual variability and trends available at some point locations (e.g., Thompson et al. 1995).

Because of this limitation, additional methods using atmospheric techniques have been examined, such as the derived moisture budget from rawinsonde data (Bromwich 1979, 1988; Bromwich and Robasky 1993; Connolley and King 1993). In recent years, the enhancement of meteorological data assimilation methods, including satellite data, has led to the use of atmospheric numerical analyses and models for the study of Antarctic precipitation and its variability (e.g., Howarth 1986; Masuda 1990; Yamazaki 1992, 1994; Arpe and Cattle 1993; Bromwich et al. 1995; Budd et al. 1995; Genthon and Braun 1995; Reid and Budd 1995; Connolley and King 1996; Walsh and McGregor 1996; Ohmura et al. 1996).
In this paper, we expand on results presented in Bromwich et al. (1995) by examining the spatial representation of net precipitation (precipitation minus evaporation/sublimation) derived from the atmospheric moisture budget of the European Centre for Medium-Range Weather Forecasts (ECMWF) analyses. A useful exercise is to intercompare fields derived from atmospheric numerical methods with synthesized observational datasets from glaciological and direct measurement methods. An intercomparison offers a means of validation as well as a qualitative measure of how well the various fields are known. Several observational and derived datasets are introduced for comparison. An appraisal of the spatial depiction and regional variability offered by available atmospheric methods is relevant to other efforts in examining Antarctic ice sheet mass balance, including the use of satellite altimetry data and potential glaciological field studies such as ITASE (International Trans-Antarctic Scientific Expedition, Mayewski 1996). This evaluation is also of interest to modelers in assessing the quality and sources of available validation data. Some of the key issues to be addressed by this study are 


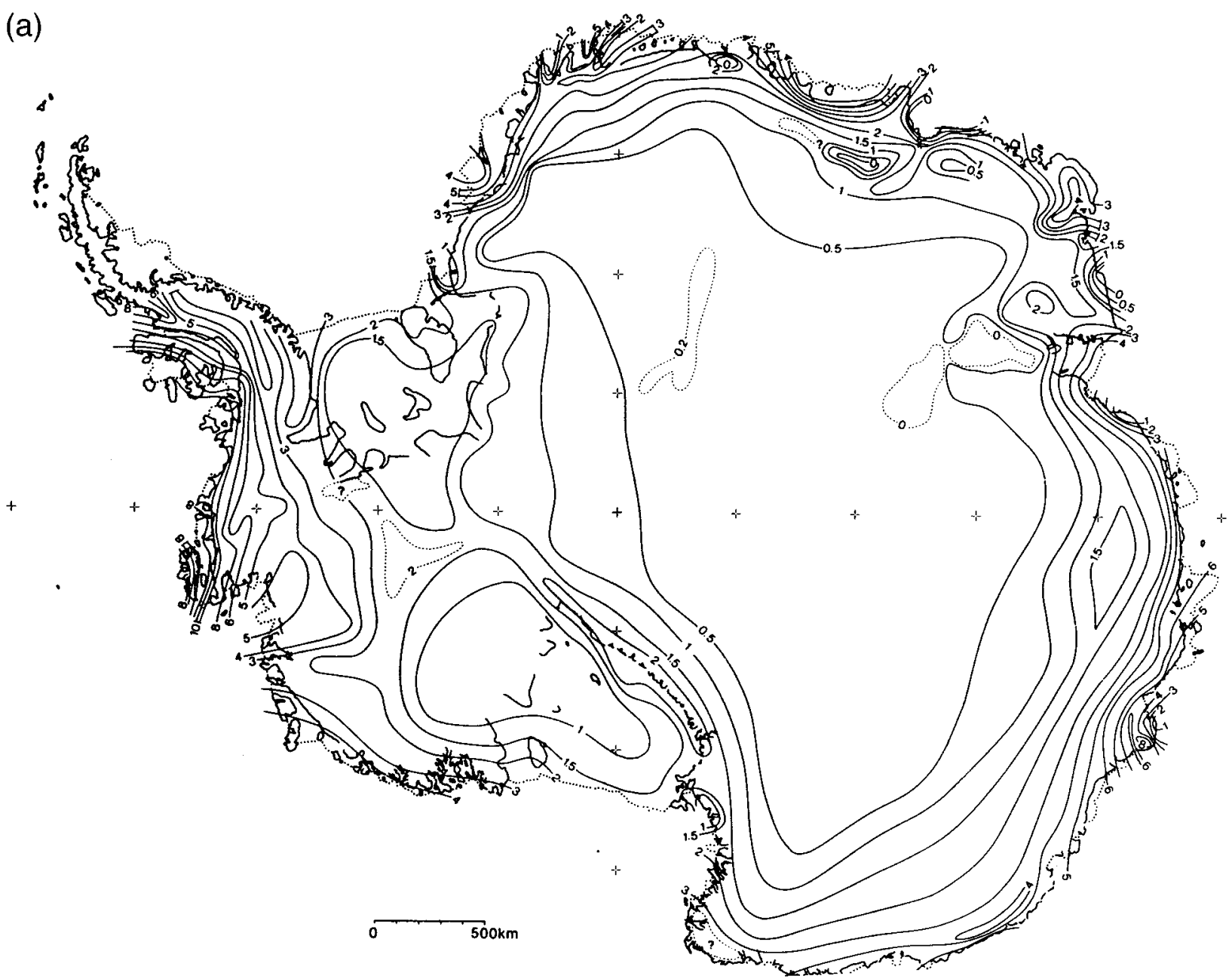

Fig. 2. Giovinetto and Bentley (1985) long-term accumulation distribution: (a) as drawn in w.e. (water equivalent) units of $100 \mathrm{~mm}^{-1} \mathrm{r}^{-1}$;

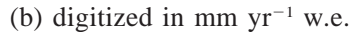

- What are the qualitative and quantitative differences in the spatial distributions of the datasets?

- What is the annual and interannual variability of Antarctic precipitation on regional scales?

- Are the causes for the observed variations in the atmospheric moisture budget apparent?

\section{Previous study}

Accumulation and precipitation are related using (Bromwich 1988)

$$
\overline{\langle B\rangle}=\overline{\langle P\rangle}-\overline{\langle E\rangle}-\overline{\langle D\rangle}-\overline{\langle M\rangle},
$$

where angled brackets represent an areal average and the overbar represents a time average, $B$ is accumulation, $P$ is precipitation, $E$ is the net of sublimation minus deposition of hoarfrost, $D$ is the divergence of snow drift, and $M$ is the divergence of meltwater runoff. The first two terms on the right-hand side are hereafter referred to as net precipitation (precipitation minus net sublimation). In estimating ice sheet mass balance, the areal accumulation rate is balanced against iceberg calving and basal melting at the bottom of ice shelves. A review of these terms is given by Jacobs et al. (1992). The dominant term in (1) is precipitation, and, to a first order, the spatial distributions of $B, P$, and $P-E$ have been thought to be comparable (Bromwich 1988), although the magnitudes are known to be different (e.g., Stearns and Weidner 1993).

Since the International Geophysical Year (IGY, 195758), the estimation of accumulation has been part of most glaciological expeditions in the Antarctic. Several recent estimates from South Pole, Dome C, Plateau Remote, and Wilkes Land are summarized by Thompson et al. (1995). Although year-to-year variability is not presented, the combined results imply an increase in accumulation during the last $30 \mathrm{yr}$. Enomoto (1991) has reviewed accumulation data from ice cores and snow pits at eight Antarctic stations. Possible relations between the long-term variability in snow accumulation 


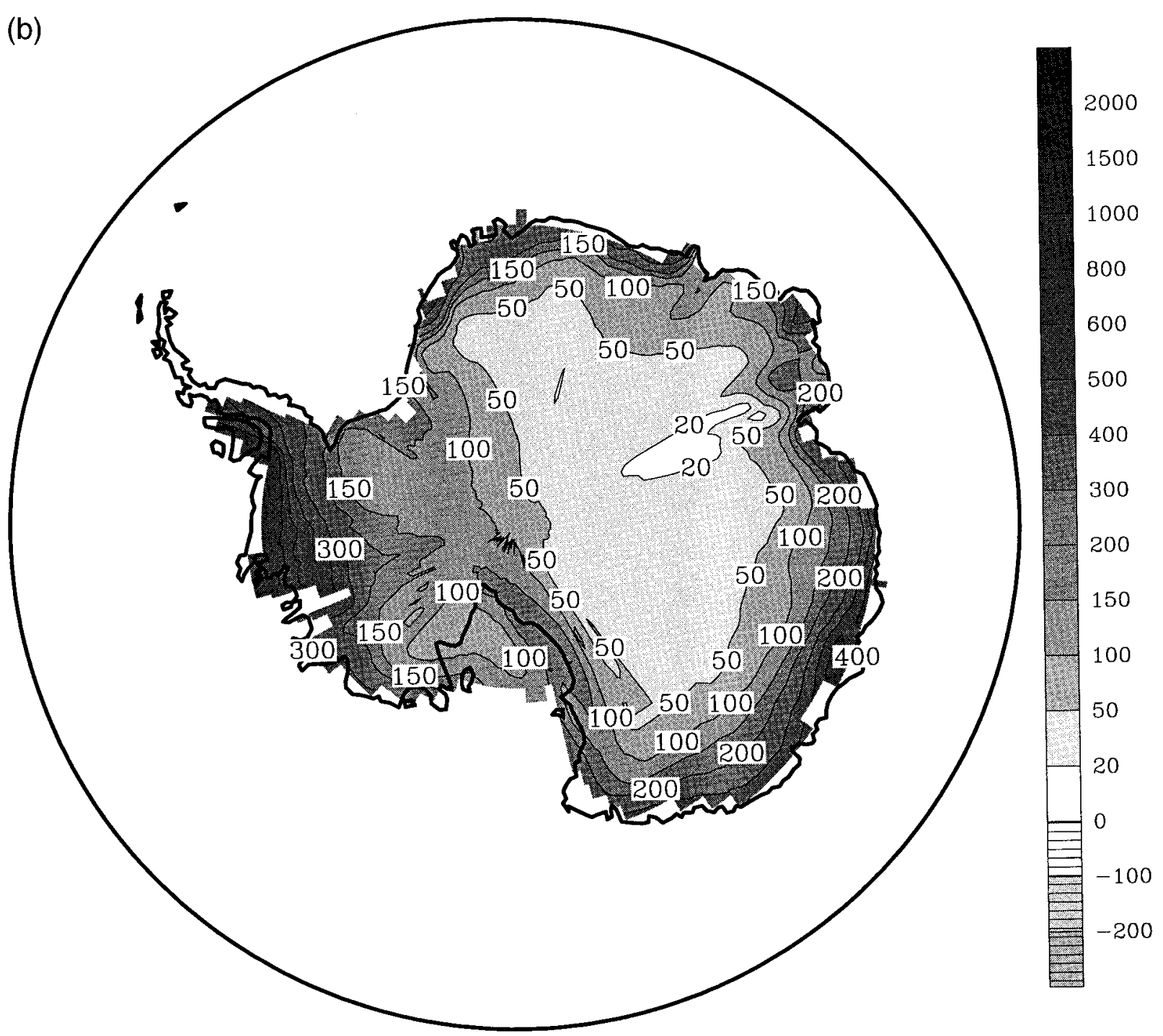

FIG. 2. (Continued)

and midlatitude sea level pressure were evaluated. A relation between precipitation gauge measurements for the Antarctic Peninsula region and the semiannual oscillation of the Antarctic circumpolar trough has been described by van Loon (1972; see also van Loon 1967). This relation was also found in a comprehensive review of variability in the observed precipitation frequency for the Antarctic Peninsula region given by Turner et al. (1997).

Numerous authors have previously synthesized glaciological data into a single, long-term annual accumulation depiction for the Antarctic continent. Compilations produced over the $1960-85$ period are discussed by Giovinetto and Bull (1987) and have evolved considerably as the number of available observations has increased. These depictions generally indicate a strong dependence of accumulation on elevation-from relatively large values for the east Antarctic coastal escarpment and low elevations in west Antarctica, to essentially desert-like conditions over the interior plateau of east Antarctica. For reference, Fig. 1 shows the Antarctic continent contoured using the Drewry elevation dataset (Drewry 1983). The most recent accumulation compilation (Giovinetto and Bentley 1985; hereafter, GB85), shown in Fig. 2a, is a manual synthesis of over 1200 data points. It differs from previous work in that the lowest accumulation values of less than $50 \mathrm{~mm} \mathrm{yr}^{-1}$ extend over a much larger area than has been previously depicted (Bromwich 1988). This figure has been frequently used for model and analyses validation (Tzeng et al. 1994; Budd et al. 1995; Connolley and King 1996; Ohmura et al. 1996). In Fig. 2b, the GB85 depiction has been digitized by assigning the contour values to $0.5^{\circ} \times 0.5^{\circ}$ boxes and interpolating the remaining grid. 


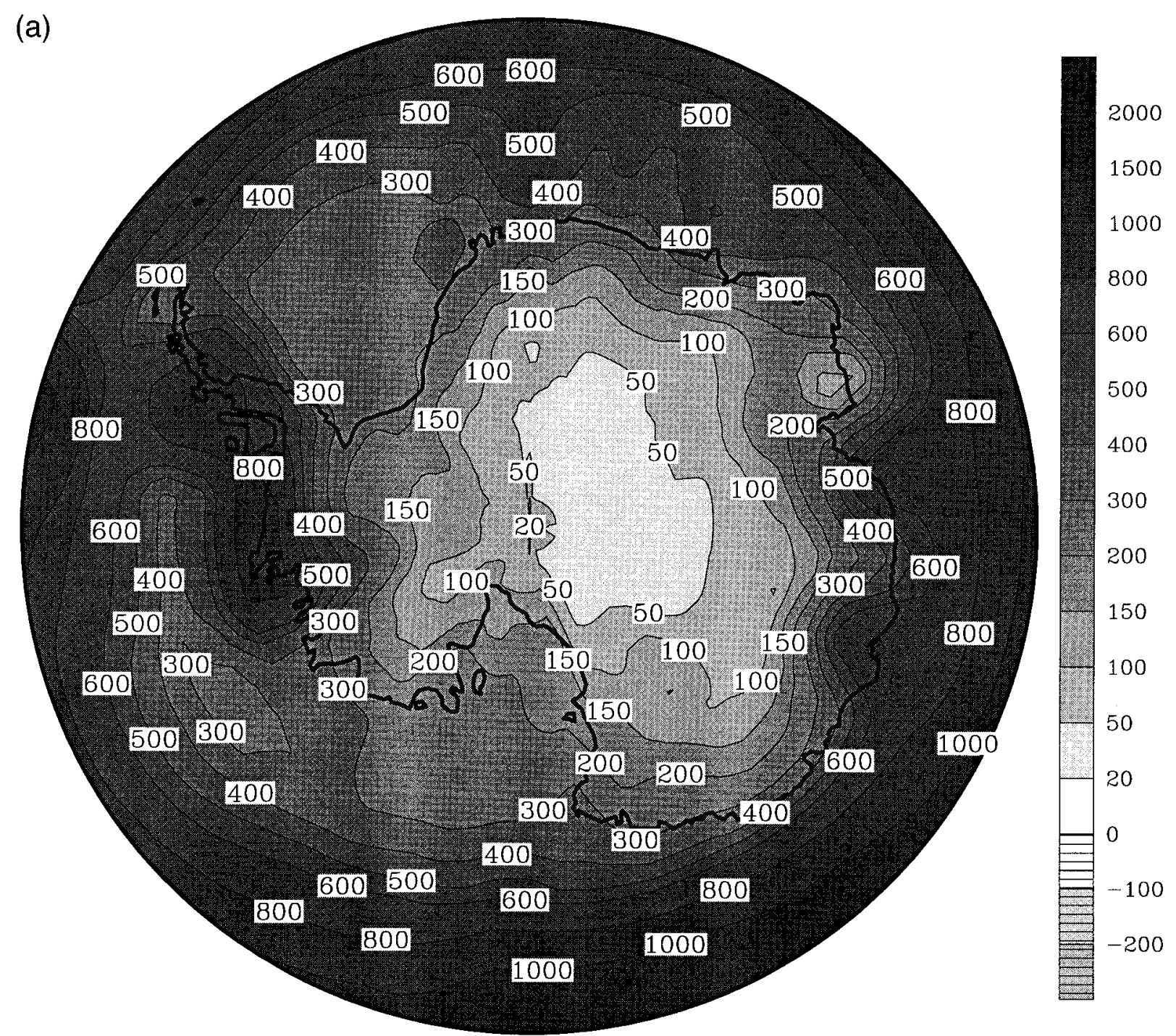

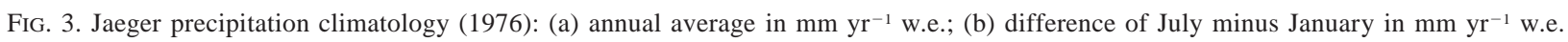

Part of the distortion between Figs. $2 \mathrm{a}$ and $2 \mathrm{~b}$ arises from the lack of minimum values for enclosed contours. This creates areas of constant values, with which a contouring program has difficulty. Over the high plateau, values of $30 \mathrm{~mm} \mathrm{yr}^{-1}$ have been added to the featureless central ridge of the ice sheet for a more realistic depiction. The resulting dataset is in reasonable agreement with the manual analysis of Giovinetto and Bentley.

At least two regional studies have provided results that are in significant disagreement with the GB85. Frolich (1992) determined values for the Antarctic Peninsula region to be nearly twice that depicted in the synthesis. The revised values for this region result in a $7 \%$ increase for the entire continental area. Goodwin (1995) and Higham et al. (1997) have also examined the Lambert Glacier Basin inland of the Amery Ice Shelf. Although the revised distribution confirms the low accumulation values for the area, Higham et al. (1997) describe an area of ablation (annual accumulation $<0$ ) confined only to the Lambert Glacier surface, while GB85 show an additional lobe of values less than zero extending to the south of the basin rim. Higham et al. (1997) is significant because it establishes values in a region where contradictory accumulation distributions (Allison 1979; McIntyre 1985) had previously been reported between which GB85 had to choose. Recent validation by Zwally and Giovinetto (1995) using passive microwave data has also found GB85 values to be low, particularly in west Antarctica. While these studies suggest a need for a revised accumulation distribution for the continent, GB85 is the best synthesis of glaciological data currently available. These studies also point to the hazards of synthesizing a long-term variable for regions 


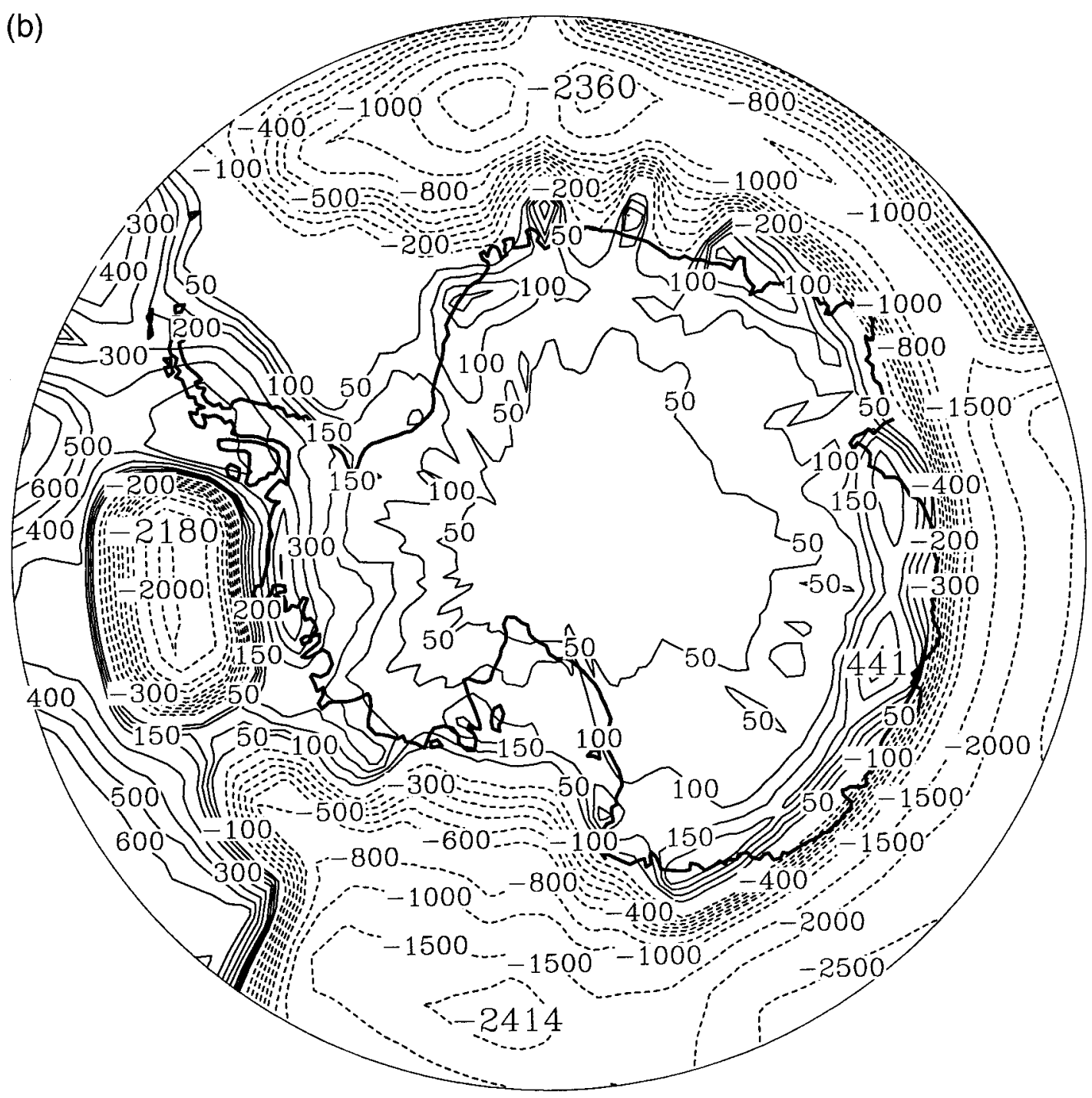

FIG. 3. (Continued)

where values are susceptible to interannual variability. Zwally and Giovinetto (1995) have estimated that GB85 is representative of periods with an overall range between 1940 and 1976.

Additional sources of precipitation data are several global climatologies that have been compiled for purposes of model validation; only a few actually depict values for the Antarctic continent, however. The Jaeger climatology (1976), obtained from the National Centers for Environmental Prediction (NCEP), formerly the National Meteorological Center-National Center for Atmospheric Research (NCAR) Reanalysis CD-ROM (Kalnay et al. 1996), is shown in Fig. 3a. Annually averaged, Fig. 3a is qualitatively similar to the accumulation synthesis of Cameron (1964), indicating larger values in Wilkes Land and a general dependence on elevation and distance to the coast. Unlike the accu- mulation plot of GB85, monthly depictions of precipitation are available from the Jaeger dataset. Figure $3 \mathrm{~b}$ shows the July minus January seasonal variation. All locations on the continent and adjacent ice shelves show larger values during the austral winter than summer, although the situation is dramatically reversed offshore with some locations experiencing annual variations of $2 \mathrm{~m} \mathrm{yr}^{-1}$ or more for some locations south of $60^{\circ} \mathrm{S}$.

As noted previously, direct precipitation gauge estimates for the Antarctic continent are inflicted with numerous errors associated with wind biases. A recent effort to correct gauge errors in a global climatology has been made by Legates and Willmott (1990; data obtained from NCAR, also available from NCEPNCAR CD-ROM). In the Antarctic, the most severe obstacle to a corrected climatology is the sparseness in observing stations. Many polar stations forego standard 


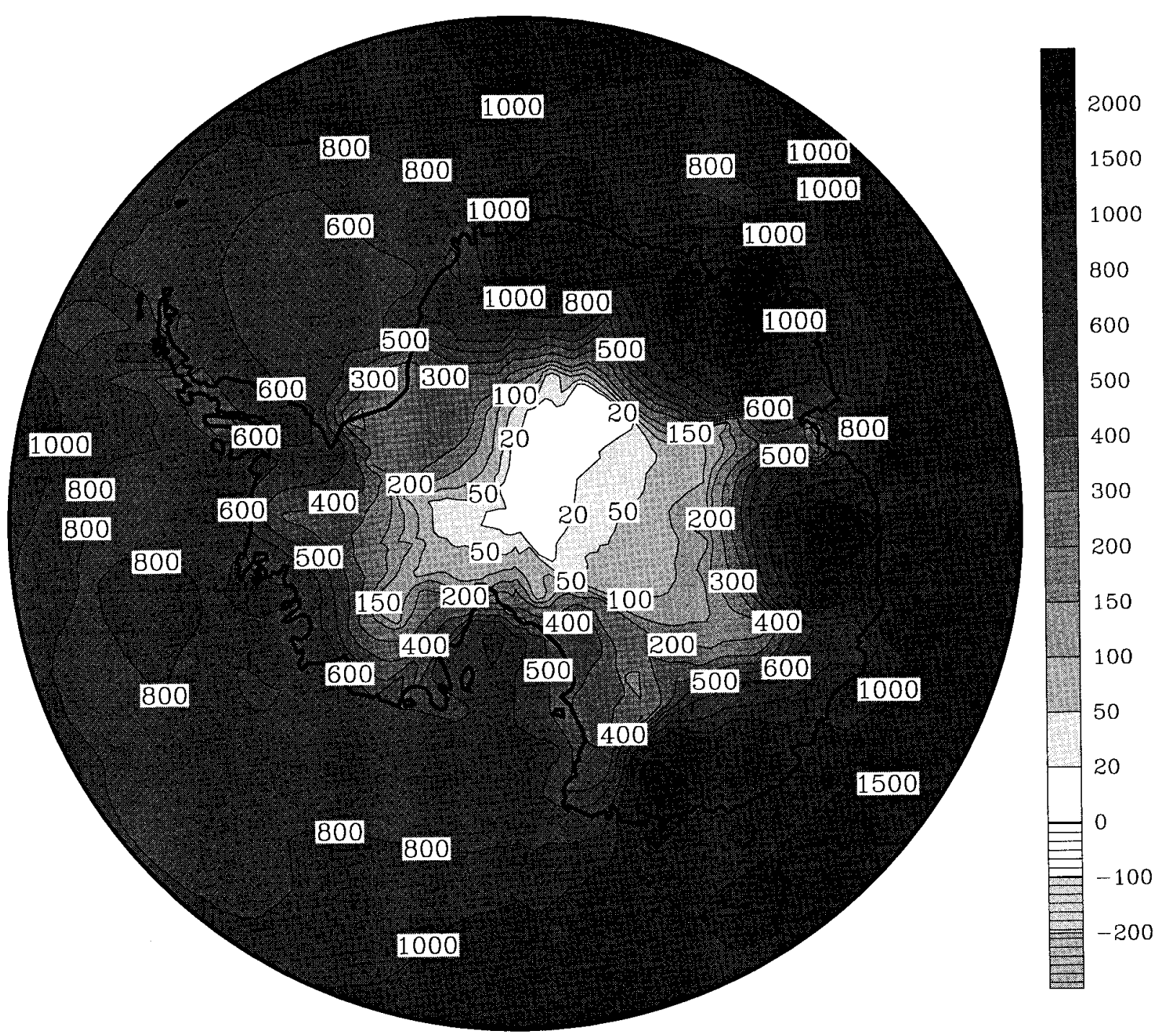

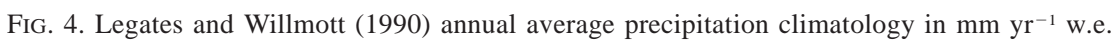

meteorological precipitation observations because of the uncertainty involved with the measurements (Schwerdtfeger 1984), and the resulting number of available Antarctic stations is meager, with a large concentration in the vicinity of the Antarctic Peninsula (Legates and Willmott 1990, see their Fig. 1). The record for these stations is also very short, some as short as $5 \mathrm{yr}$ (D. R. Legates 1997, personal communication). The contoured Legates and Willmott climatology, shown in Fig. 4, contains large discrepancies with the climatologies previously shown, which appear to result from the sparseness of interior data points. In particular, the sharp gradient associated with the coastal escarpment is not as clearly defined as in GB85 or Jaeger (1976), and the precipitation quantities are extremely large in comparison to the GB85 accumulation values. Given the sparseness of gauge measurements on the continent, these discrep- ancies are to be expected. A synthesis of gauge measurements from former Soviet stations has also been produced by Bryazgin (1982), with a discussion of errors associated with gauge measurements. The Bryazgin composition was supplemented by available glaciological data, however.

Use of the atmospheric moisture budget for net precipitation estimations in Antarctica has a relatively recent history. Several studies have examined the moisture budget from a global or hemispheric perspective (e.g., Starr et al. 1969; Peixoto and Oort 1983). Bromwich (1979, 1988, 1990) and Bromwich et al. (1995) utilized the existing east Antarctic coast rawinsonde network to estimate $P-E$ for a sector defined from $0^{\circ}-110^{\circ} \mathrm{E}$ and $68.4^{\circ}-78.2^{\circ} \mathrm{S}$. The results indicate good agreement with glaciological data when the entire rawinsonde network is utilized. The area has been evaluated separately by 


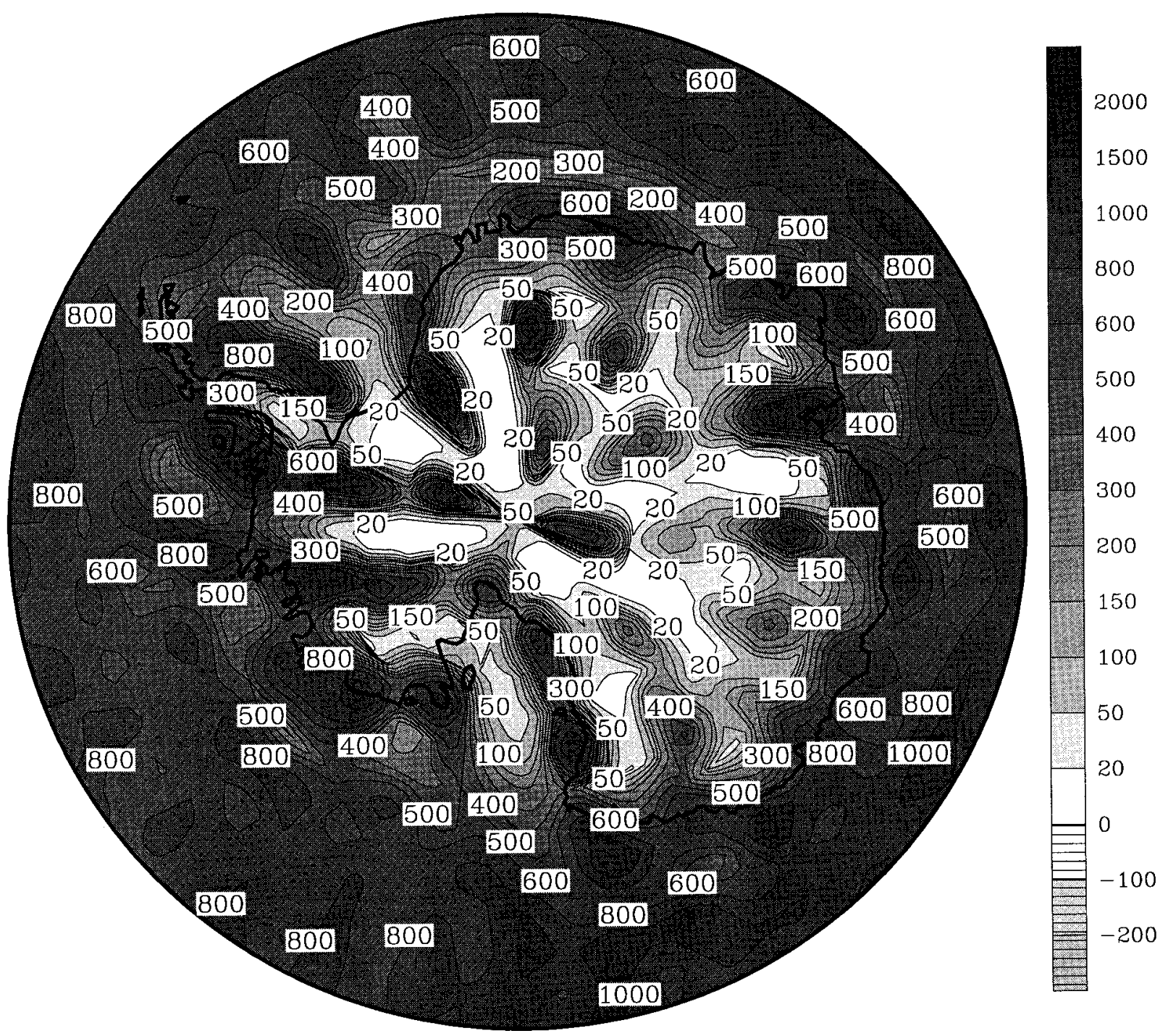

FIG. 5. Annual average of precipitation field from the NCEP-NCAR Reanalysis for $1982-94$ in $\mathrm{mm} \mathrm{yr}^{-1} \mathrm{w.e}$.

Connelley and King (1993, 1996). In comparison to the glaciological estimate for the region and selected results from the United Kingdom Meteorological Office Unified Climate Model, Connelley and King (1996) found the rawinsonde method overestimates sector accumulation; however, the treatment of the rawinsonde transports differs with that employed by Bromwich (1988, $1990)$. Bromwich utilized the SANAE station $\left(70.3^{\circ} \mathrm{S}\right.$, $\left.2.4^{\circ} \mathrm{W}\right)$ to compute a zonal transport across the western boundary, while Connolley and King assume cancellation of fluxes across the sector east and west boundaries. The observational network nevertheless offers a means of validating time-varying net precipitation estimations with rawinsonde-derived values.

A final source of precipitation data considered here is the output precipitation rate of a numerical weather prediction model for an ensemble of short-term (6 or
$12 \mathrm{~h})$ forecasts. These predictions are more model dependent than the analyzed fields (Kalnay et al. 1996; Genthon and Braun 1995; Arpe and Cattle 1993). Genthon and Braun (1995) have recently analyzed the ECMWF ensemble forecast precipitation for 1985-91. Genthon and Braun indicate that the ECMWF depiction "does a fairly good job" with the atmosphere-surface water exchange over ice sheets. Precipitation fields have also been produced as the result of the expanded datasets made available from reanalysis projects. In particular, the results of the NCEP-NCAR Reanalysis have recently been made available for an extended period of time from 1982 94 (Kalnay et al. 1996). The NCEP-NCAR Reanalysis is of interest due to the project's eventual goals of producing analyses that extend for 1957-96. Antarctic analyses produced over this period may take advan- 


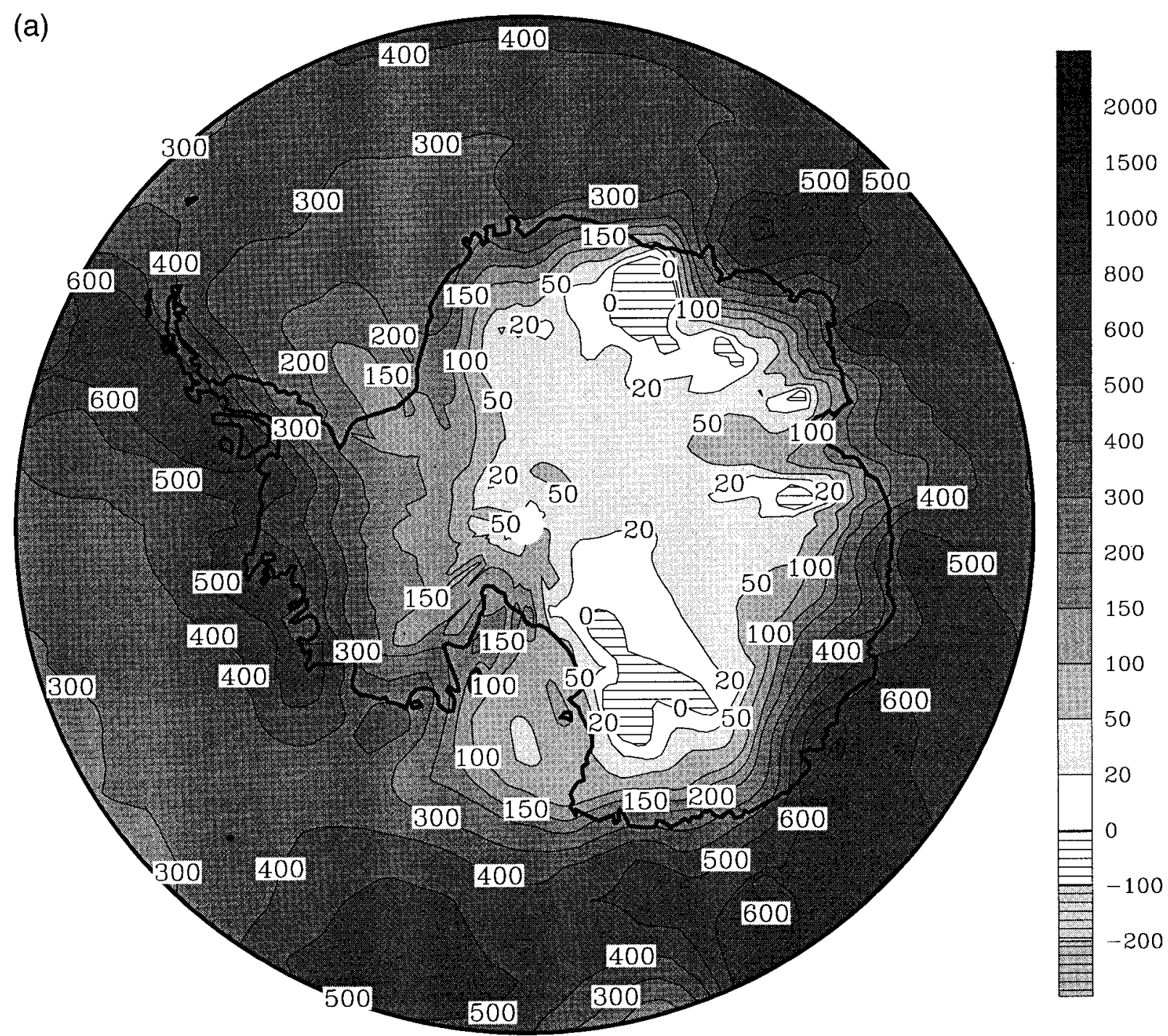

FIG. 6. (a) ECMWF net precipitation $(P-E)$ averaged for 1985-95, corrected for atmospheric mass balance in $\mathrm{mm}^{-1} \mathrm{yr}^{-1}$ w.e. The figure has been smoothed using a 300-km radius; (b) ECMWF corrected net precipitation minus uncorrected net precipitation averaged for 1985-

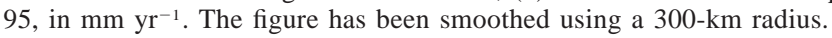

tage of a substantial atmospheric observational network in the years of, and for the decades following, the IGY. In high southern latitudes, however, there are two major concerns regarding the present Reanalysis dataset. First, the incorporation of manually derived sea level pressure observations, known as PAOBs (for a discussion see Seaman et al. 1993), have been misincorporated during the data assimilation. These point estimates are produced in a regular spacing of 1000-1500 km over the Southern Hemisphere, with additional points to locate troughs and ridges. Over Antarctica, the extreme elevation of the continent diminishes the physical meaning of the sea level pressure field, implying that the PAOBs errors may be at least partially mitigated over the continent. Ad- ditionally, the presence of other sources of observational data will nearly always supersede the low priority given to PAOBs during quality control procedures. Second, perhaps more importantly, errors associated with polar moisture fields have been recently investigated (R. Kistler, M. Iredell, and H. Pan 1996, personal communication). A simplification in the moisture diffusion parameterization used by the assimilation model leads to a spurious wave pattern in the polar regions. The impact on the reanalysis precipitation field is shown to be significant in Cullather et al. (1996, see their Fig. 10). Figure 5 shows the average precipitation field with the spectral distortion clearly visible. In the presence of such large spatial errors, an examination of the evaporation field is de- 


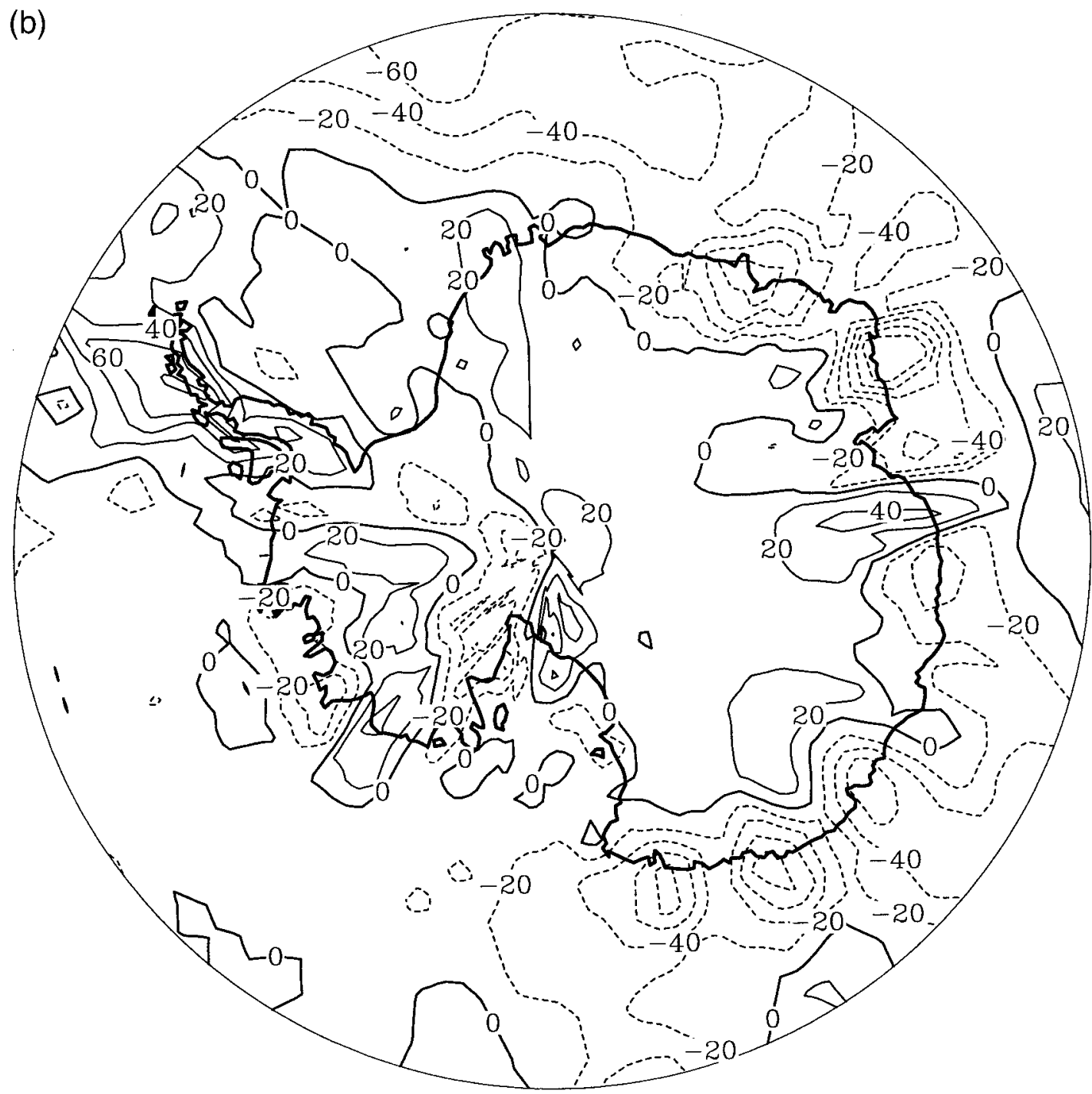

FIG. 6. (Continued)

ferred. A reasonable representation of the precipitation field may be retrieved if the data are filtered (M. Serreze 1996, personal communication) or if a sufficiently large area is averaged (W. N. Ebisuzaki 1996, personal communication). Nevertheless, these two errors argue for considerable caution in evaluating results.

\section{Atmospheric moisture budget from analyses}

The atmospheric moisture budget may be written as

$$
P-E=-\frac{\partial W}{\partial t}-\nabla \cdot \frac{1}{g} \int_{P_{\mathrm{top}}}^{P_{\mathrm{sfc}}} q \mathbf{V} d p,
$$

where $W$ is precipitable water, $P_{\text {sfc }}$ is surface pressure, $q$ is specific humidity, and $\mathbf{V}$ is the horizontal wind vector. The variable $P_{\text {top }}$ is the highest level of the at- mosphere that is not zero in the analyses. In the ECMWF analyses, velocity data extend to $10 \mathrm{hPa}$, while atmospheric moisture is considered negligible above 300 hPa. Equation (2) is written so that the residual $P-E$ is positive for comparison with glaciological accumulation. The first term on the right-hand side is the time derivative of precipitable water and is referred to as the storage term. The second term may be rewritten as the flux of vertically integrated moisture transports across a specified horizontal boundary using

$$
\langle P-E\rangle=-\left\langle\frac{\partial W}{\partial t}\right\rangle-\frac{1}{A} \oint\left(\int_{P_{\mathrm{top}}}^{P_{\mathrm{sfc}}} \frac{q \mathbf{V}}{g} d p\right) \cdot \mathbf{n} d l,
$$

where $A$ is the area of interest, and $\mathbf{n}$ is the outward pointing normal vector of the area perimeter. Four adjacent grid points are used to define an area and bound- 


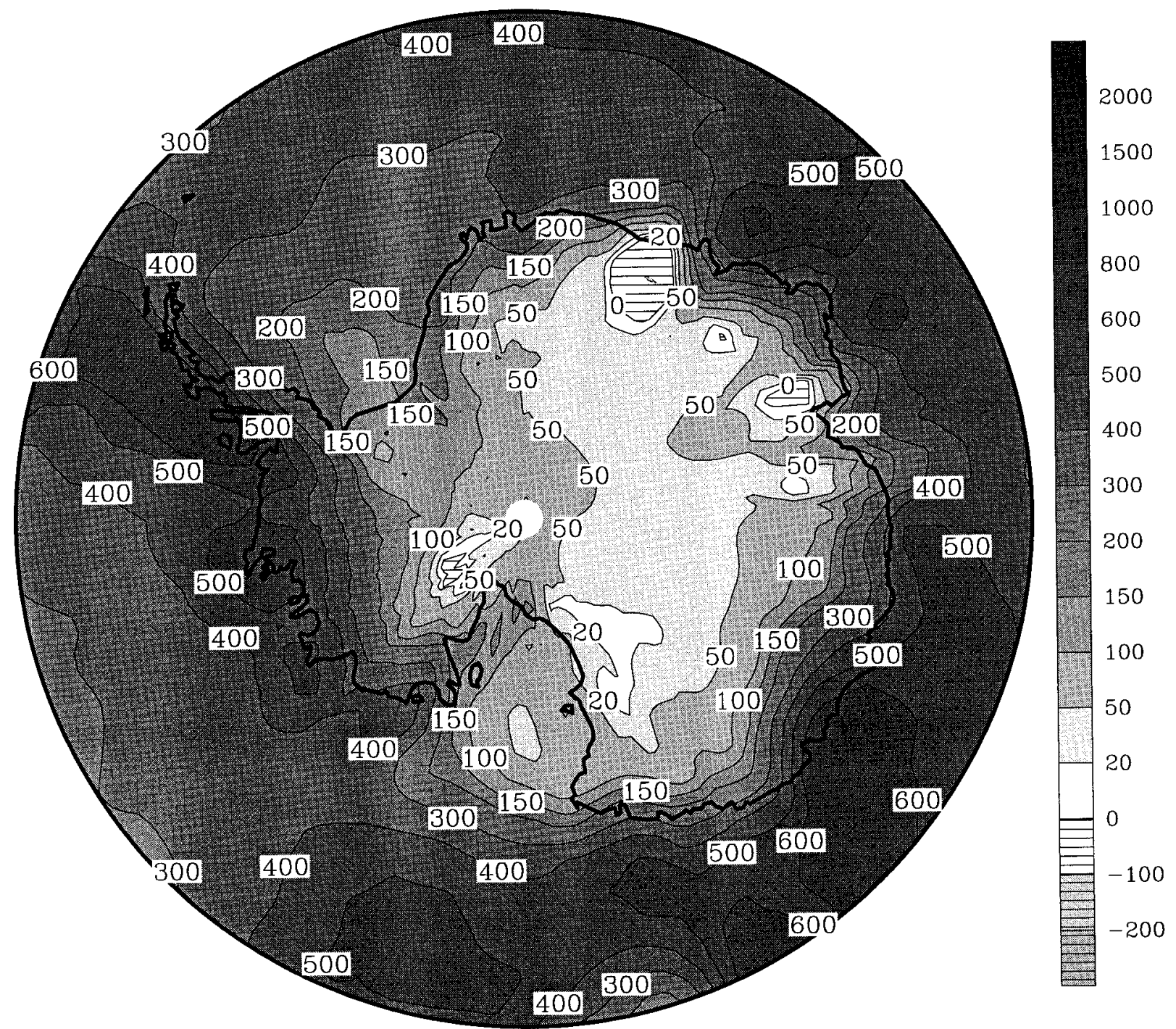

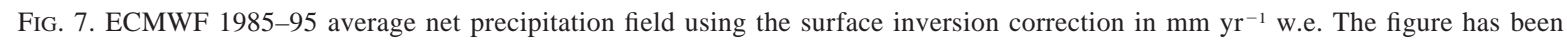
smoothed using a $300-\mathrm{km}$ radius.

ary. The units of (3) are $\mathrm{kg} \mathrm{m}^{-2} \mathrm{~s}^{-1}$, which is equivalent to the rate of $\mathrm{mm} \mathrm{s}^{-1}$ of water-equivalent precipitation. An additional Reynolds decomposition of the second right-hand side term into mean and eddy components may be performed after temporal averaging of (3) using the covariance of $q$ and $\mathbf{V}$ :

$$
\overline{q \mathrm{~V}}=\bar{q} \overline{\mathrm{V}}+\overline{q^{\prime} \mathbf{V}^{\prime}}
$$

where the transient term is defined as

$$
\overline{q^{\prime} \mathbf{V}^{\prime}}=\frac{\sum_{i=1, n}\left(q_{i}-\bar{q}\right)\left(\mathbf{V}_{i}-\overline{\mathbf{V}}\right)}{n}
$$

The use of (4) in (3) results in

$$
\begin{aligned}
\overline{\langle P-E\rangle} & \\
= & -\overline{\left\langle\frac{\partial W}{\partial t}\right\rangle} \\
& -\frac{1}{A} \oint\left[\left(\int_{\overline{P_{\mathrm{top}}}}^{\overline{P_{\mathrm{scc}}}} \frac{\bar{q} \overline{\mathbf{V}}}{g} d p\right)+\left(\int_{\overline{P_{\mathrm{top}}}}^{\overline{P_{\mathrm{sfc}}}} \frac{\overline{q^{\prime} \mathbf{V}^{\prime}}}{g} d p\right)+K\right] \cdot \mathbf{n} d l .
\end{aligned}
$$

The additional term $K$ arises because, strictly,

$$
\overline{\int_{P_{\text {top }}}^{P_{\text {sfc }}} \frac{q \mathbf{V}}{g} d p} \neq \int_{\overline{P_{\text {top }}}}^{\overline{P_{\text {sfc }}}} \frac{\overline{q \mathbf{V}}}{g} d p .
$$

In practice, however, $K$ is considered negligible. 


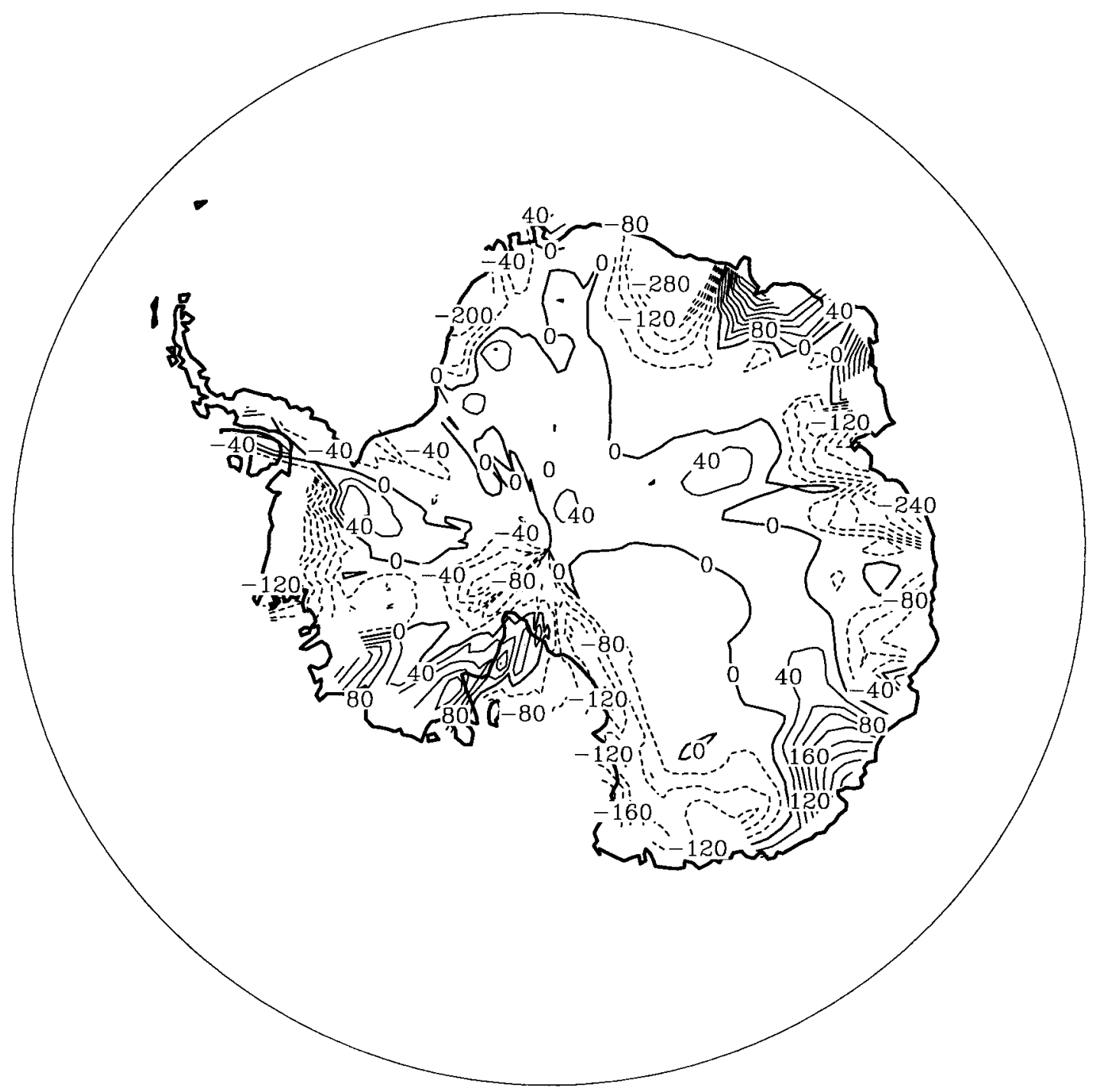

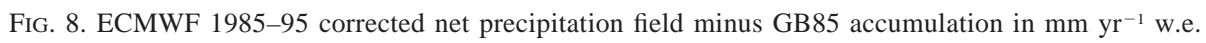

The moisture budget from analyses has been examined from a global perspective (Oki et al. 1993; Trenberth and Guillemot 1995; Dodd and James 1996). In Trenberth and Guillemot (1995), the ECMWF and NCEP analyses were evaluated for the period 1985-93. Substantial differences between the two analyses as well as artificial trends were found, particularly in the Tropics, where the effects of limited diurnal resolution and the model cumulus parameterization can be significant. In Bromwich et al. (1995), the atmospheric moisture budgets derived from operational numerical analyses of the ECMWF, NCEP, and the Australian Bureau of Meteorology (BoM) were intercompared over high southern latitudes. The comparison indicated that analyses produced by the ECMWF more closely reproduce time-averaged glaciological data and rawinsonde values at each level.
The results presented in Bromwich et al. (1995) were limited to the continental scale. Several other studies have specifically examined the high southern latitude atmospheric moisture budget from analyses. Howarth (1983, 1986) and Howarth and Rayner (1986) examined the objective analyses produced by the BoM for the years 1973-78 and 1980-84. Masuda (1990) investigated the analyses from the ECMWF over the 1-yr FGGE observation period (1979). Yamazaki (1992, 1994) derived moisture fluxes from the NCEP analyses for the years 1986-90. Although the spatial depiction revealed areas of $P-E$ less than zero in the interior, Yamazaki estimated annual accumulation from this method to be $135 \pm 18 \mathrm{~mm} \mathrm{yr}^{-1}$, only slightly smaller than glaciological estimates. Rawinsonde values obtained from Syowa station $\left(69.00^{\circ} \mathrm{S}\right.$, $\left.39.58^{\circ} \mathrm{E}\right)$ were used in validation. Interestingly, the 
(a)

\section{TOTAL}

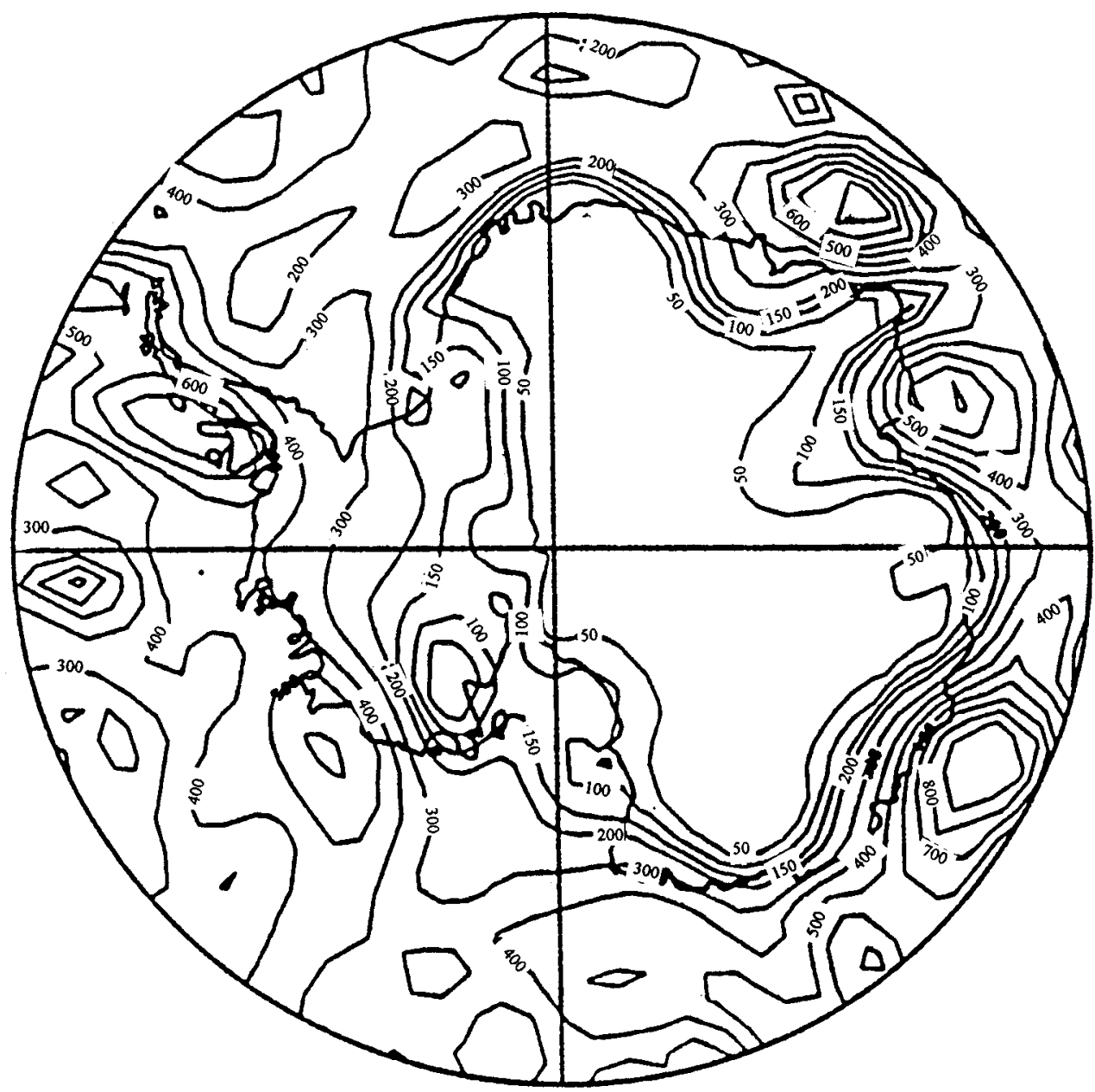

FIG. 9. (a) Total, (b) mean, (c) eddy and annual atmospheric moisture transport convergence from Reid and Budd (1995) for September 1989-November 1992 in $\mathrm{mm} \mathrm{yr}^{-1}$ w.e.

spectral wave distortion found in the NCEP-NCAR Reanalysis is not present in the NCEP operational product. This is possibly due to NCEP post-processing procedures which subsample to produce the archived $2.5^{\circ} \times 2.5^{\circ}$ grid. Budd et al. (1995) evaluated moisture fluxes derived from the Australian BoM Global Assimilation and Prediction Scheme (GASP). The GASP analyses differ from the BoM analyses evaluated by Howarth $(1983,1986)$ and Bromwich et al. (1995). The derived $P-E$ spatial pattern compared favorably to GB85. Eddy convergence was found to dominate continental net precipitation accounting for $90 \%$ of the annual total. The studies of Yamazaki (1992, 1994), Budd et al. (1995), and Bromwich et al. (1995) demonstrate the viability of this method.

The analyses used in this study are from the ECMWF Tropical Oceans Global Atmosphere Archive II, a twice-daily global $2.5^{\circ} \times 2.5^{\circ}$ dataset reported at near-surface and 14 standard pressure levels, with the lowest six containing moisture data. After 1991, the dataset includes a 15 th level at $925 \mathrm{hPa}$ but is not used here for temporal continuity. The dataset is described and evaluated by Trenberth (1992). In addition to the moisture budget study of Bromwich et al. (1995), Cullather et al. (1997) has evaluated the standard ECMWF and NCEP variables over Antarctica using available rawinsonde, automatic weather station, ship, and synthesized long-term observations. The ECMWF analyses were generally found to be superior and to reasonably depict the broad-scale atmospheric circulation. Further, Genthon and Braun (1995) have examined the temperature fields from ensemble forecasts for 1985-91 which were found to produce a reasonable spatial depiction for Antarctica. Two caveats are worth noting, however. The ECMWF surface topography, adapted from the U.S. Navy elevation dataset, is somewhat dated and in significant error in the Queen Maud Land region $\left(\sim 30^{\circ} \mathrm{W}-60^{\circ} \mathrm{E}\right)$ (Genthon and Braun 1995, see their Fig. 3). Addi- 
(b)

\section{MEAN}

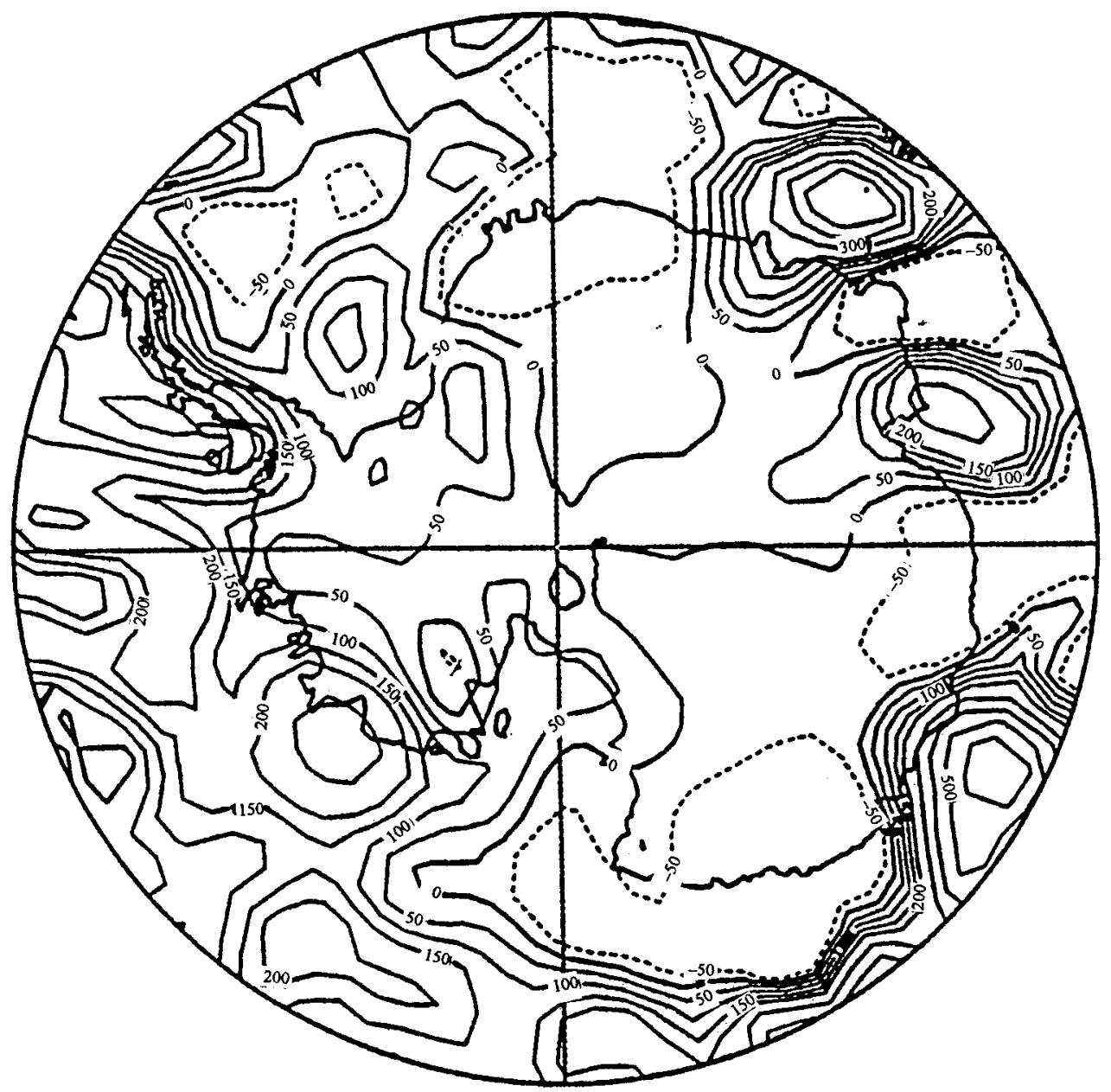

FIG. 9. (Continued)

tionally, the coarse vertical resolution of the ECMWF is inadequate to resolve the intense Antarctic surface inversion over the high plateau. This has an adverse impact on the derived moisture budget, which is described in the results section below.

There are two important considerations necessary for the accurate realization of atmospheric moisture budget equations (2), (3), and (6). The first requires a sufficient horizontal resolution to adequately capture the spatial variability of moisture transports, and this is to be addressed in comparisons with precipitation estimates from other means. The second is the issue of sufficient vertical resolution to conserve the mass of dry air and adequately determine the integrated transport. Vertical resolution is partly evaluated through the examination of the columnar dry-air mass budget. Dry-air mass is not conserved in numerical analyses (Trenberth 1991; Trenberth and Solomon 1994; Trenberth et al. 1995). The method for correcting the divergent wind used here follows Tren- berth (1991). The conservation of columnar dry-air mass may be expressed as

$$
\begin{aligned}
\left(\frac{\partial P_{\text {sfc }}}{\partial t}-g \frac{\partial W}{\partial t}\right)+\nabla \cdot \mathbf{I}^{*} & =R, \\
\mathbf{I}^{*} & =\int_{P_{\text {top }}}^{P_{\text {sfc }}}(1-q) \mathbf{V}^{*} d p,
\end{aligned}
$$

where $R$ is the erroneous residual, and $\mathbf{V}^{*}$ is the original horizontal velocity field. A barotropic correction $\mathbf{V}^{\mathbf{c}}$ is assumed such that at each level

$$
\mathbf{V}=\mathbf{V}^{*}-\mathbf{V}^{c} \text {. }
$$

Trenberth (1991) introduces a potential function to solve directly for $\mathbf{V}^{c}$, producing a corrected velocity field:

$$
\begin{aligned}
X^{c} & =\nabla^{-2} R, \\
\mathbf{V}^{c} & =\frac{\nabla X^{c}}{P_{\text {sfc }}-P_{\text {top }}-g W} .
\end{aligned}
$$


(c)

\section{EDDY}

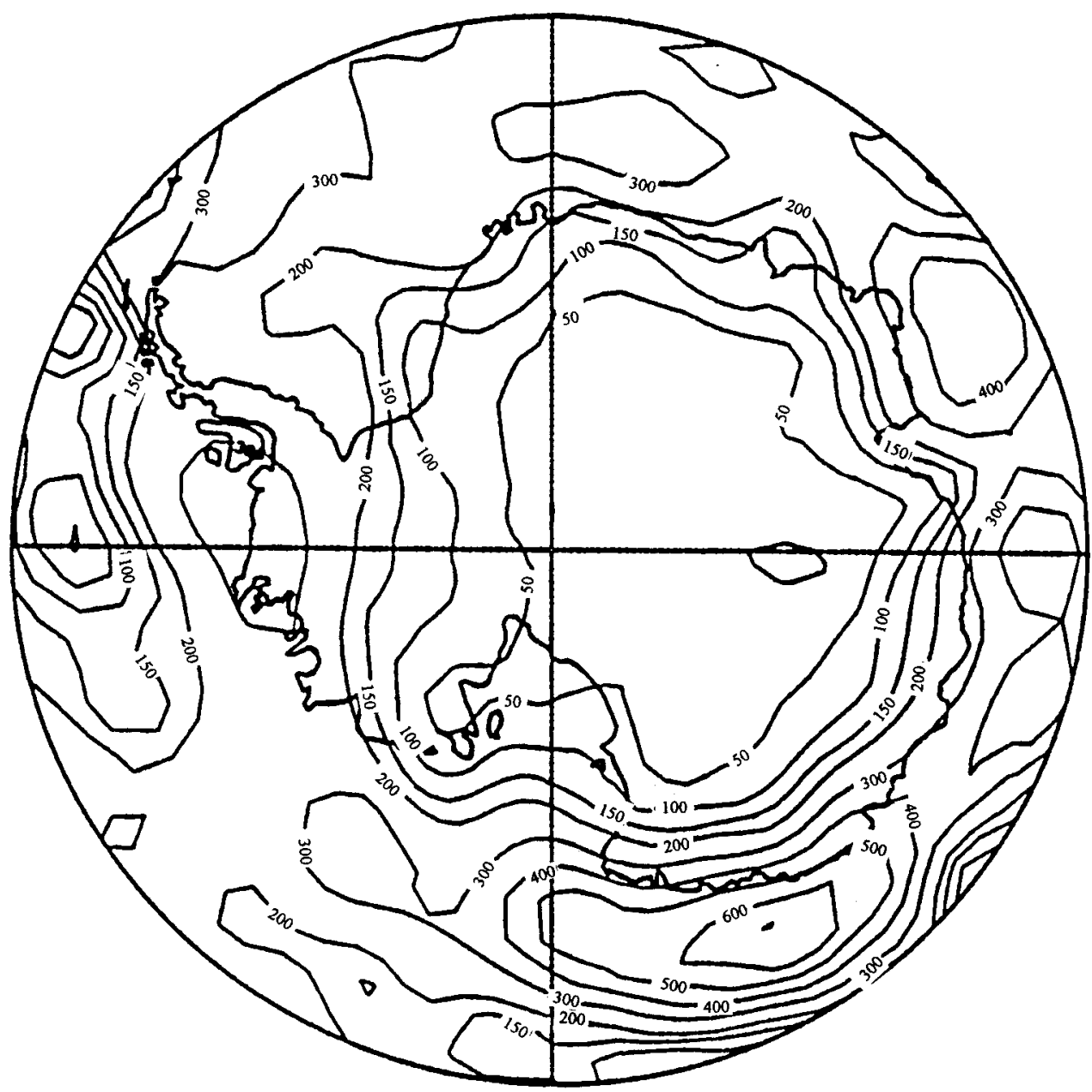

FIG. 9. (Continued)

Alternatively, the two terms of the left-hand side of (8) may be set equal by iteratively modifying the value of I* locally to produce $\mathbf{I}$ such that $R=0$. This was performed to avoid repeated transformations from grid point to spectral space.

In gridpoint space on a spherical surface, the inverse Laplacian operation, required in (10), will incur an error unless the grid meets an orthogonality criterion (Swarztrauber 1974), and in this case it almost never does. A typical solution method for this scenario is to perturb the constant value in the generalized Helmholtz equation until a solution is achieved, but here again the initial field $R$ is typically too noisy to result in an adequate solution. The inverse Laplacian operation is avoided by directly solving for $\mathbf{I}$ using (8). A procedure outlined by Endlich (1967; see also Stephens 1967; Hurrell 1990) produces a nondivergent vector field. It may be readily modified so that the vector field $\mathbf{I}$ is set to a particular divergence specified by the first term of (8):

$$
\begin{aligned}
-\left(\frac{\partial P_{\text {sfc }}}{\partial t}-g \frac{\partial W}{\partial t}\right) & =\nabla \cdot \mathbf{I} \\
\mathbf{I} & =\int_{P_{\mathrm{top}}}^{P_{\mathrm{sfc}}}(1-q)\left(\mathbf{V}^{*}-\mathbf{V}^{c}\right) d p .
\end{aligned}
$$

Once the corrected vector field $\mathbf{I}$ is determined, $\mathbf{V}^{c}$ may be solved for and the winds corrected:

$$
\begin{aligned}
\mathbf{I} & =\mathbf{I}^{*}-\mathbf{V}^{c} \int_{P_{\mathrm{top}}}^{P_{\mathrm{sfc}}}(1-q) d p, \\
\mathbf{V}^{c} & =\frac{\mathbf{I}^{*}-\mathbf{I}}{\int_{P_{\mathrm{top}}}^{P_{\mathrm{sfc}}}(1-q) d p} .
\end{aligned}
$$

The Endlich procedure is documented for a rectangular grid; it is apparent that convergence on a latitude-longitude grid in polar regions requires the assumption that 
TABLE 1. Comparison of recent estimates of Antarctic precipitation.

\begin{tabular}{|c|c|c|c|}
\hline Study & Estimate & Method & Value $\left[\mathrm{mm} \mathrm{yr}^{-1}\right]$ \\
\hline Giovinetto and Bentley (1985) & Accumulation & Glaciological data synthesis. & $143 \pm 14$ \\
\hline Frolich (1992) & Accumulation & Glaciological data correction to GB85. & $156 \pm 17$ \\
\hline Warrick et al. (1995)* & Accumulation & Glaciological data synthesis. & 162 \\
\hline Bromwich (1990) & $P-E$ & Synthesis of GB85 and atmospheric data. & $151-156$ \\
\hline Bromwich (1990) & $P-E$ & $\begin{array}{l}\text { Atmospheric moisture budget from } \\
\text { ECMWF, } 1979 \text { from Masuda (1990) cor- } \\
\text { rected for Antarctic area. }\end{array}$ & 136 \\
\hline Yamazaki (1992) & $P-E$ & $\begin{array}{l}\text { Atmospheric moisture budget from NCEP } \\
\text { analyses, 1986-90. }\end{array}$ & $135 \pm 18$ \\
\hline Genthon and Braun (1995) & $P-E$ & $\begin{array}{l}\text { ECMWF ensemble 6-h forecast precipita- } \\
\text { tion minus evaporation, } 1985-91 .\end{array}$ & 139 \\
\hline Budd et al. (1995) & $P-E$ & $\begin{array}{l}\text { Atmospheric moisture budget from GASP } \\
\text { analyses, 1989-92. }\end{array}$ & 157 \\
\hline Connolley and King (1996) & $P-E$ & $\begin{array}{l}\text { Modeled atmospheric moisture budget } \\
\text { from U.K. Met. Office Unified Clim. } \\
\text { Model. }\end{array}$ & 184 \\
\hline Ohmura et al.* (1996) & $P-E$ & $\begin{array}{l}\text { Modeled precipitation minus evaporation } \\
\text { from ECHAM coupled model. }\end{array}$ & 197 \\
\hline This study & $P-E$ & $\begin{array}{l}\text { Atmospheric moisture budget from } \\
\text { ECMWF, 1985-95. }\end{array}$ & $151 \pm 13$ \\
\hline This study & $P$ & Jaeger (1976) climatology. & 197 \\
\hline This study & $P$ & $\begin{array}{l}\text { NCEP-NCAR Reanalysis (Kalnay et al. } \\
\text { 1996), 1982-94. }\end{array}$ & $335 \pm 14$ \\
\hline This study & $P$ & Legates-Wilmott (1990) climatology. & 596 \\
\hline
\end{tabular}

* Area considered possibly differs from that employed by GB85.

the contribution to the local corrections in $x$ (longitude) and $y$ (latitude) be proportional to the grid spacing. The assumptions involved in writing (9), carried over from Trenberth (1991), are that the error is in the divergent wind, that the correction is barotropic, and that the trapezoidal rule used for the vertical integration is appropriate. Trenberth et al. (1995) outlines more comprehensive procedures for correcting mass balance at each level. This has not been attempted here; using the above assumptions, however, a first-order assessment of columnar mass balance is made below.

\section{Results}

\section{a. Correction methods and long-term averaged spatial distribution}

A long-term (11 yr) averaged net precipitation field derived from ECMWF analyses for Antarctica is shown in Fig. 6a. To account for spurious patterns associated with the convergence of meridians, the field has been smoothed to a constant radius of $300 \mathrm{~km}$. Figure $6 \mathrm{~b}$ shows the impact of the atmospheric mass balance correction. At middle and low latitudes, the correction reveals a pattern associated with the semidiurnal tide (Trenberth 1991). For Antarctica, the spatial distribution in Fig. $6 \mathrm{~b}$ partially implicates the katabatic wind regime along the coastal escarpment. In the vertical integration, the near-surface katabatic flow becomes overemphasized due to the coarse vertical resolution of the analyses. The maximum vertical extent of the katabatic wind regime has been estimated at $300 \mathrm{~m}$ (Schwerdtfeger 1984) with the strongest winds occurring much lower.
This error generates an overestimate for the convergence zones surrounding the continental escarpment. The general pattern does not change substantially with the annual cycle, although the correction is largest in winter. The correction is found to be typically small but can be significant locally.

A second problem with the vertical resolution is found over the high interior plateau. The numerical analyses are insufficient to resolve the very strong Antarctic nearsurface inversion in winter. This is important to the regional moisture budget, because the very-low moisture content below the inversion will become exaggerated in the vertical integration. The inversion strength may be estimated by using the lowest two analyses levels that are at least $500 \mathrm{~m}$ above the surface to extrapolate a temperature $T_{\mathrm{sfc}+500 \mathrm{~m}}$. The inversion strength $T_{\mathrm{inv}}$ is then obtained from

$$
T_{\mathrm{inv}}=T_{\mathrm{sfc}+500 \mathrm{~m}}-T_{\mathrm{sfc}+2 \mathrm{~m}},
$$

where $T_{\mathrm{sfc}+2 \mathrm{~m}}$ is the analyzed near-surface temperature. An ad hoc correction is applied to monthly averaged, atmospheric mass balance-corrected values for $T_{\text {inv }}>$ $10^{\circ} \mathrm{C}$. In this case, the moisture transports for $500 \mathrm{~m}$ above the surface are derived similar to $T_{\mathrm{sfc}+500 \mathrm{~m}}$, and a pressure value for the 500-m level is determined from the hypsometric equation. The transports are then vertically integrated from the 500-m level, while the layer between the surface and $500 \mathrm{~m}$ is assumed to contain negligible moisture. The revised net precipitation field, averaged for 1985-95, is shown in Fig. 7. Moisture values for the high plateau region are generally small so that the correction is essentially insignificant for the 


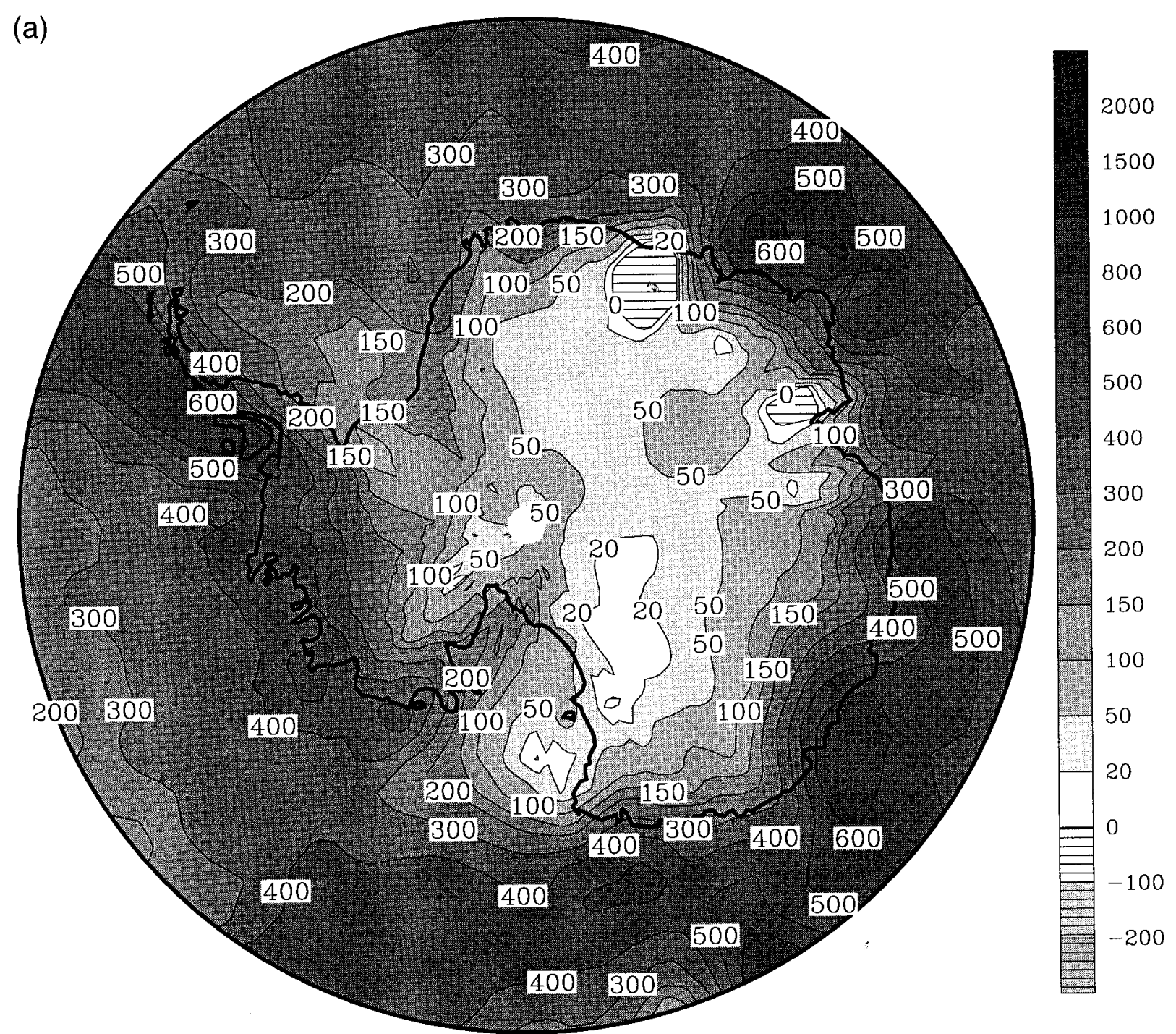

FIG. 10. (a) Total, (b) mean, (c) eddy and annual atmospheric moisture transport convergence from ECMWF analyses for September 1989-November 1992 in $\mathrm{mm} \mathrm{yr}^{-1}$ w.e. The figures have been smoothed using a 300-km radius.

continental average. However, the correction method does produce a more realistic spatial distribution for the Antarctic interior (Fig. 7). An independent test of the correction methods is to compare the resulting field with the ensemble forecast precipitation shown in Genthon and Braun (1995, see their Fig. 6); although hydrologic balance cannot be presumed for the ECMWF model, there appears to be very close agreement between the two fields. Comparisons of the numerical analyses with mesoscale modeling results (Hines et al. 1997, see their Fig. 2) indicate that the addition of a $600-\mathrm{hPa}$ level is desirable to adequately resolve the inversion over Antarctica. This difficulty with the nearsurface inversion may explain deficiencies in the net precipitation patterns of other studies, particularly with regard to large spurious regions of $P-E<0$ over the high interior (Yamazaki 1992, 1994).
The required corrections applied for the dry-air columnar mass balance and for the near-surface inversion illustrate the limitations of this method. Nevertheless, the spatial distribution of annual net precipitation shown in Fig. 7 appears to be reasonable, and the discrepancies with the long-term glaciological synthesis are of interest. The figure shows low values

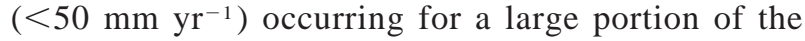
interior high plateau, with much larger values along the east Antarctic coastal escarpment and in west Antarctica, and the largest values present along the west coast of the Antarctic Peninsula which are locally greater than $800 \mathrm{~mm} \mathrm{yr}^{-1}$. This describes the observed large-scale representation of Antarctic accumulation.

In Fig. 8, the averaged $P-E$ field derived from the ECMWF is subtracted from the digitized GB85 field shown in Fig. 2b. Not surprisingly, the largest errors 


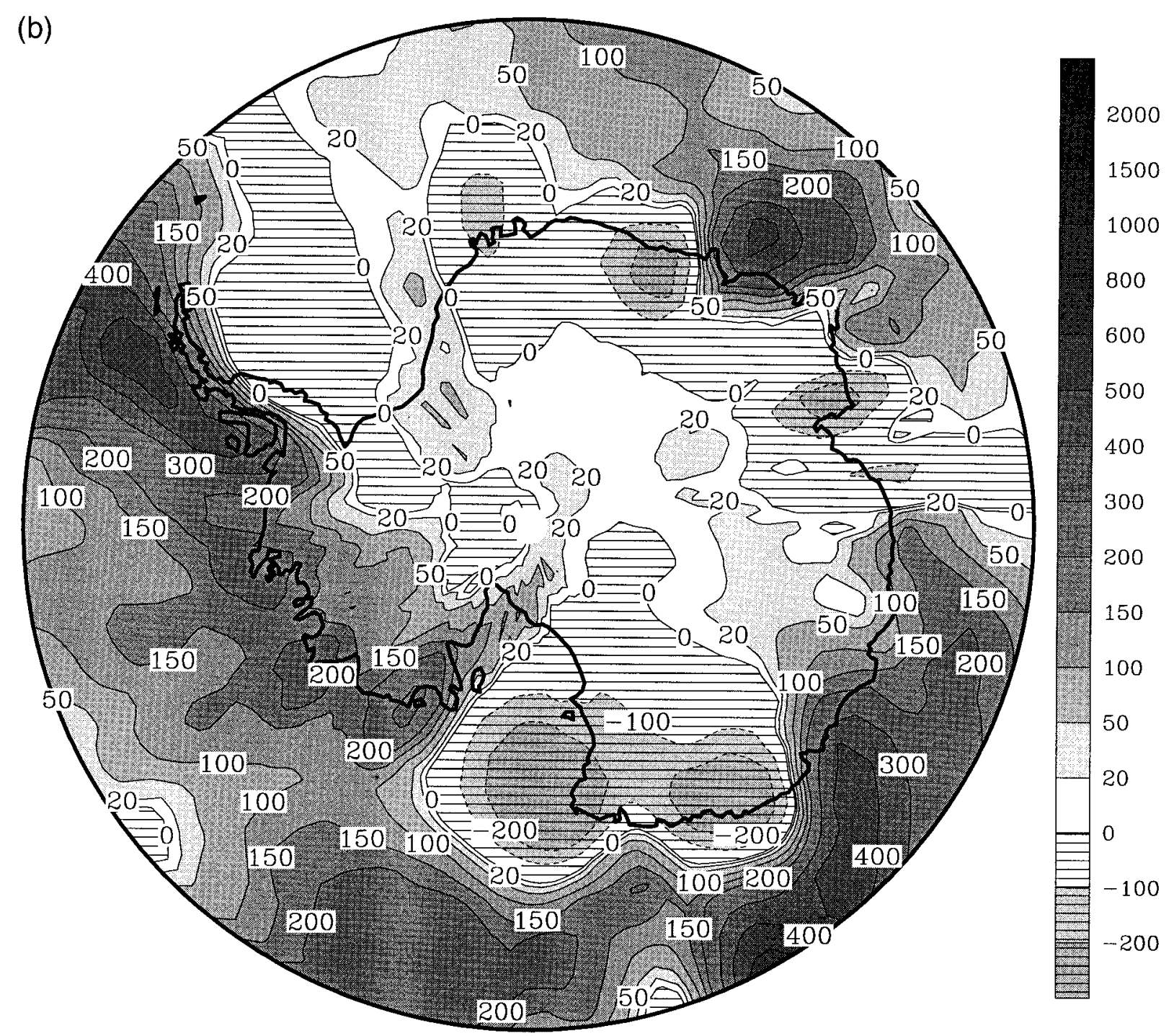

FIG. 10. (Continued)

are associated with the coastal regions, while the central interior generally appears to be in agreement. The largest differences, greater than $320 \mathrm{~mm} \mathrm{yr}^{-1}$, are located near Porpoise Bay $\left(\sim 130^{\circ} \mathrm{E}\right)$ and inconveniently fall between glaciological observations near Casey $\left(110.5^{\circ} \mathrm{E}\right)$ and Dumont d'Urville $\left(140.0^{\circ} \mathrm{E}\right)$. In east Antarctica, some of the differences appear to be associated with poor positioning. This is particularly true for the coastal region from $10^{\circ}-50^{\circ} \mathrm{E}$, where large negative values are immediately adjacent to large positive values. Perhaps the most troubling discrepancy in the spatial pattern is the lack of larger values associated with the orographic belt adjacent to the Transantarctic Mountains located along the western and southern edges of the Ross Ice Shelf. The spatial representation of $P-E$ over the Ross Ice Shelf is in substantial disagreement with glaciological observations. The absence of an orographi- cally induced precipitation belt along the Transantarctic Mountains is a specific discrepancy, which is clearly shown as negative value contours on the difference map. Values larger than $200 \mathrm{~mm} \mathrm{yr}^{-1}$ are plotted in GB85 for this area. The GB85 map shows a lobe of values less than $100 \mathrm{~mm} \mathrm{yr}^{-1}$ extending across the Ross Ice Shelf and into west Antarctica, while Fig. 7 shows a definite transition between conditions on the Ice Shelf and west Antarctica, with a line of values greater than $100 \mathrm{~mm}$ $\mathrm{yr}^{-1}$ extending parallel to the eastern edge of the Ross Ice Shelf. Differences with accumulation data may result from analyses error, interdecadal variability (e.g., Cullather et al. 1996), or a combination; there is insufficient information to determine the exact cause. Unlike other regions of Antarctica, the Ross Ice Shelf has been comprehensively examined as part of the Ross Ice Shelf Project (RISP; Thomas et al. 1984) of the U.S. Antarctic 


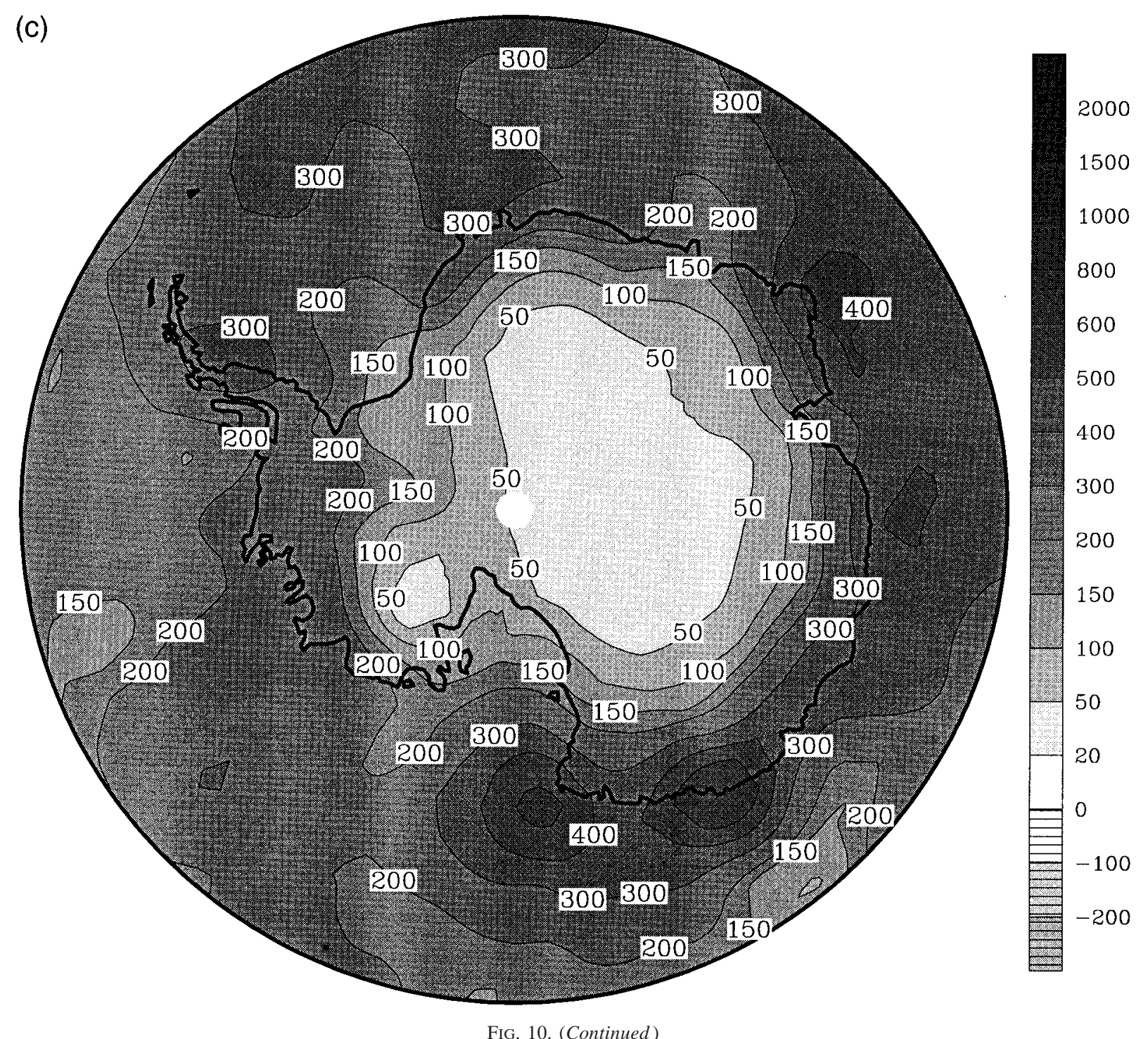

Program. Twenty-year ice cores were obtained at high spatial resolution over the duration of the project from 1973-78. The synthesized RISP accumulation map is reflected in the GB85 distribution. The spatial distribution from other analyses (e.g., Budd et al. 1995) also do not show the orographic maximum near the Transantarctic Mountains, perhaps indicating that the analyses are not of high-enough spatial resolution to reproduce the feature.

Three areas of negative $P-E$ are present near the continental perimeter. The largest, in Queen Maud Land (near $72^{\circ} \mathrm{S}, 30^{\circ} \mathrm{E}$ ), roughly approximates the location of a zero accumulation contour in GB85; however, the size of the region shown in Fig. 7 is several times larger. Additional zero contours are found near the western edge of the Lambert Glacier $\left(70^{\circ} \mathrm{S}, 65^{\circ} \mathrm{E}\right)$ and in west Antarctica $\left(85^{\circ} \mathrm{S}, 125^{\circ} \mathrm{W}\right)$. As was previously discussed, the zero contour in GB85 south of the Lambert Glacier is now thought to be erroneous. Each of these regions is associated with a confluence zone of the katabatic wind flow (Parish and Bromwich 1991), and it is possible that wind-transported snow in these regions produces a dominant influence on the surface mass balance.

For the conterminous area of ice sheets and ice shelves defined by GB85, the 1985-95 average annual $P-E$ value is $151 \mathrm{~mm} \mathrm{yr}^{-1}$. This compares with the previously reported value of $157 \mathrm{~mm} \mathrm{yr}^{-1}$ in Bromwich et al. (1995) for the years 1985-92 which did not apply the corrections given here. Table 1 compares the revised value with others reported. Note the differences in the variables measured. The Reanalysis and the Legates and Wilmott estimates are outliers for reasons previously discussed. When these values are removed, the median becomes $155 \mathrm{~mm} \mathrm{yr}^{-1}$, with a rms of $4 \%$. This implies 


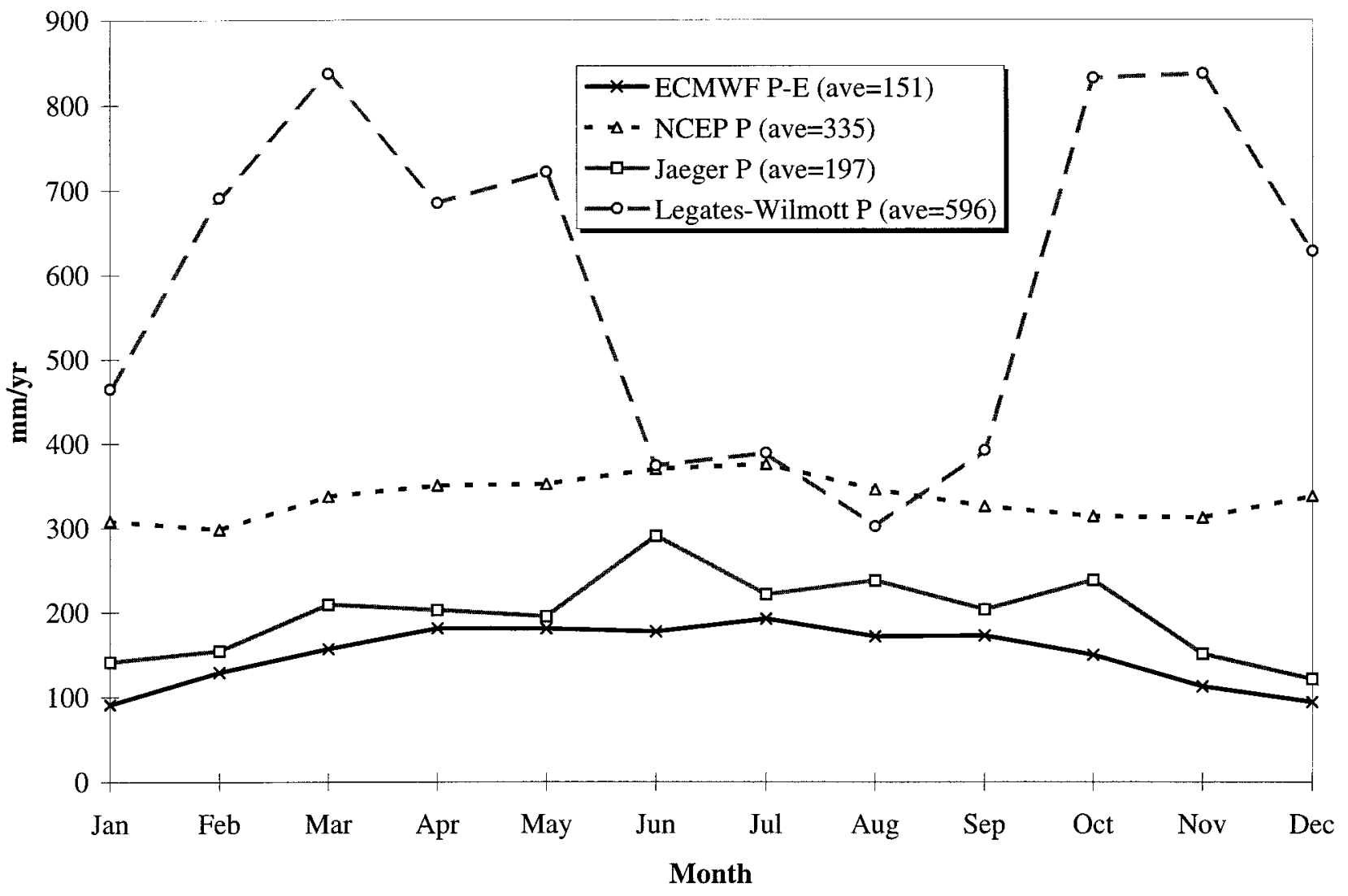

FIG. 11. Annual cycle of net precipitation derived from ECMWF for Antarctic continent in comparison to NCEP-NCAR Reanalysis pre-

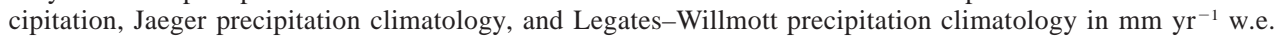

some agreement among the diagnostic methods used. Recent results produced by general circulation modeling are somewhat larger (Connolley and King 1996; Ohmura et al. 1996), but it is not clear that this is a systematic result, as there is some ambiguity in the area averaged over. Ohmura et al. (1996) compare results with an observational estimate for the region $70^{\circ} \mathrm{S}$ to the South Pole (Giovinetto et al. 1992) which encompasses oceanic areas and is hence considerably larger than the glaciological estimate for the continent.

\section{b. Transport decomposition}

Currently, only Reid and Budd (1995) have produced mean and eddy fields for comparison, and these are shown in Figs. 9 and 10 in comparison to the ECMWF fields averaged over the same time period (September 1989-November 1992). The eddy component generally dominates east Antarctic precipitation and exhibits a close relation with elevation throughout the continent. In areas of west Antarctica adjacent to the Amundsen and Bellingshausen Seas, mean and eddy components are roughly proportional (Lettau 1969; Bromwich et al. 1995). The spatial distribution of eddy activity is found to be highly de- pendent on elevation, which is consistent with the understanding of Antarctica as an orographic barrier to Southern Ocean cyclonic activity (Mechoso 1980). Maxima are located along the east Antarctic coastline, with the largest values occurring in the region from $120^{\circ} \mathrm{E}$ to the Ross Ice Shelf. This is in general agreement with Reid and Budd (1995). The mean flow is characterized by small negative values over large areas of east Antarctica. The GASP analyses appear to support the ECMWF in showing mean divergence values for the western Ross Ice Shelf. The largest mean component values, in excess of $500 \mathrm{~mm} \mathrm{yr}^{-1}$, occur along the western side of the Antarctic Peninsula. There is considerable agreement between analyses for mean convergence maxima near Porpoise Bay and Syowa Station. The ECMWF and GASP analyses, however, are in marked disagreement in the Amery Ice Shelf region. Mean atmospheric moisture transport convergence in the ECMWF analyses for this region is negative, with a minimum of less than -100 $\mathrm{mm} \mathrm{yr}^{-1}$. The GASP analyses are strongly positive for the same region, with maxima greater than 250 $\mathrm{mm} \mathrm{yr}^{-1}$. This is surprising given the agreement of principal features in other locations. The distribution of values given by Higham et al. (1997, see his Fig. 
(a)

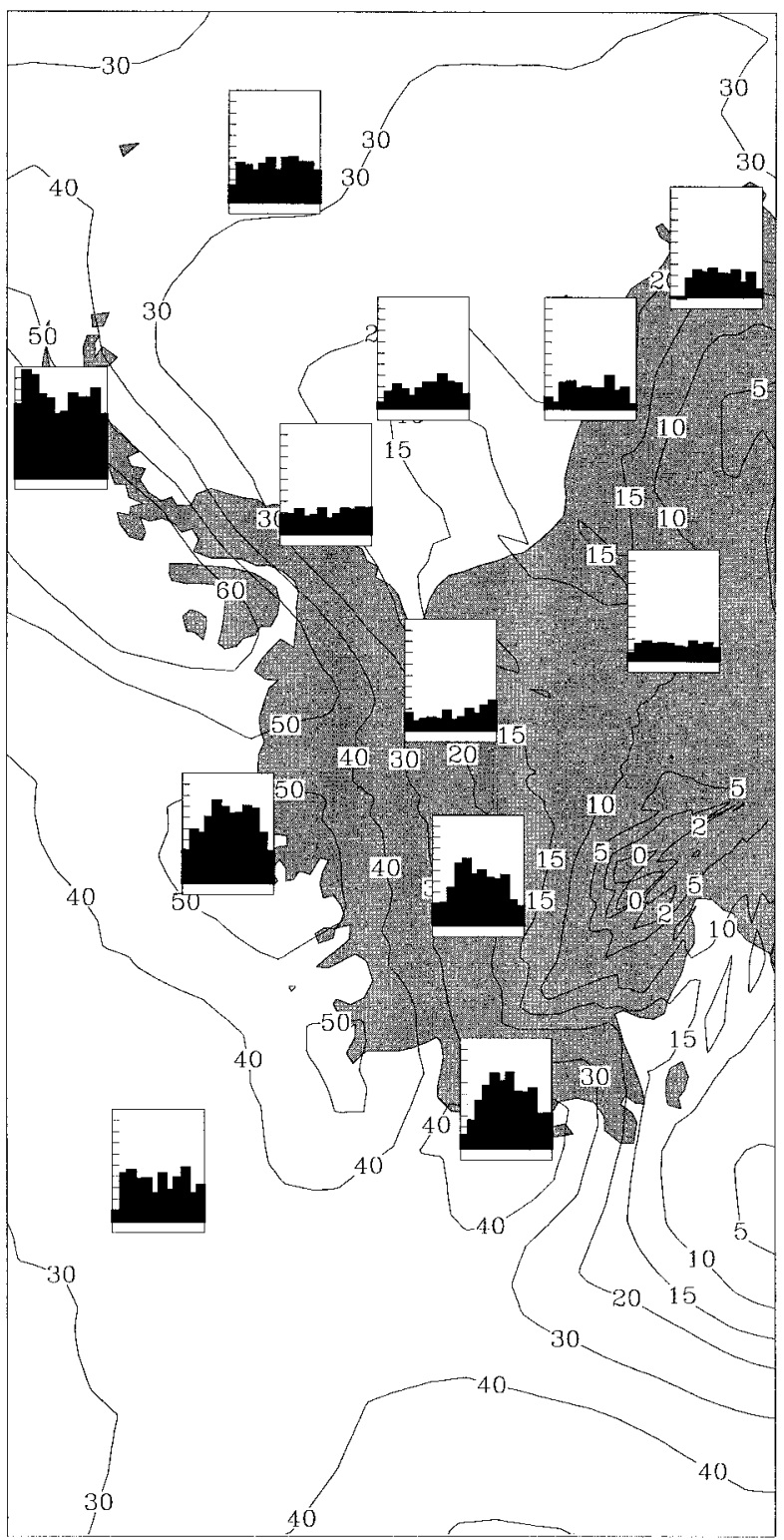

(b)

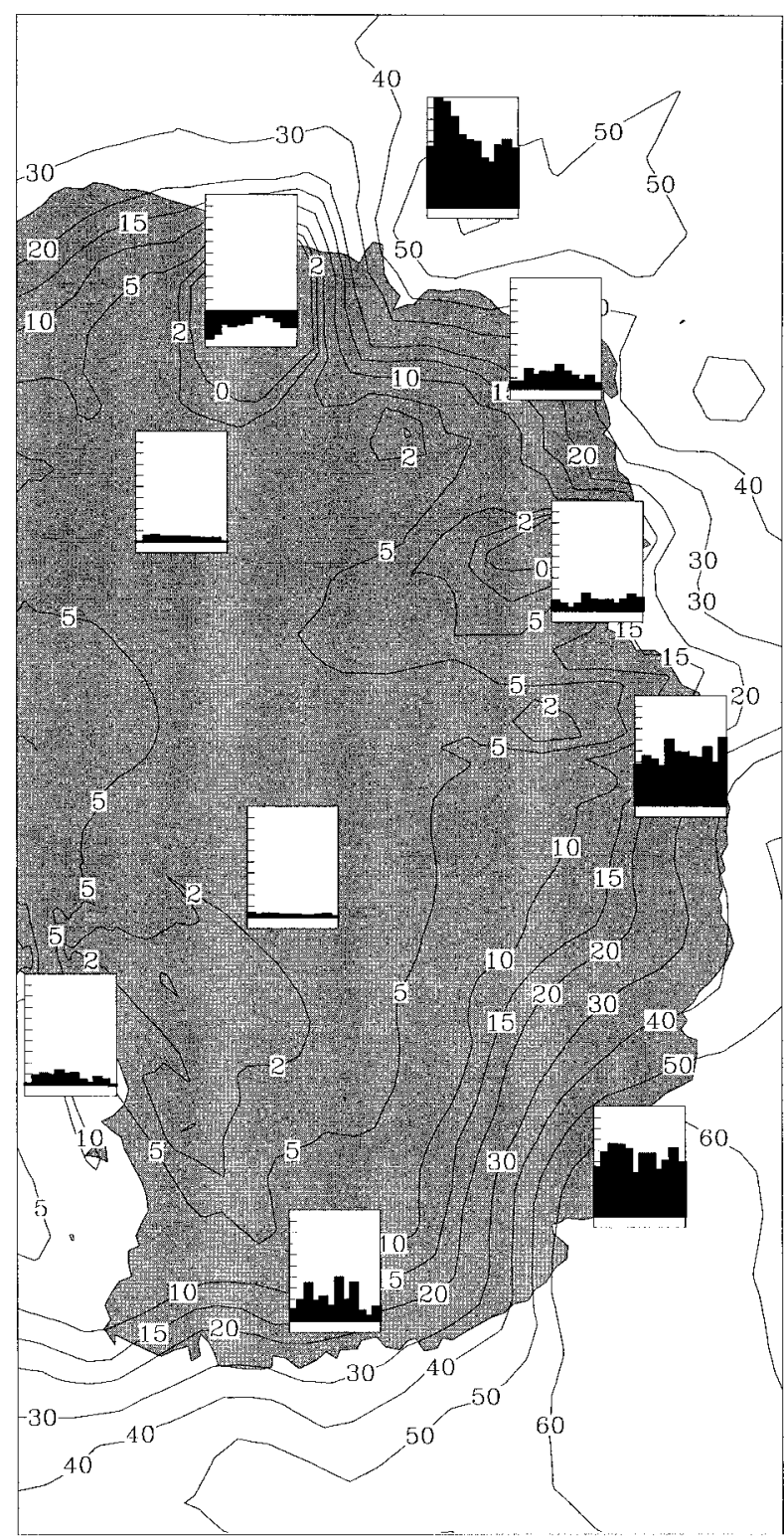

FIG. 12. Long-term ECMWF $P-E$ and annual cycles (February-January) for various locations in (a) west and (b) east Antarctica.

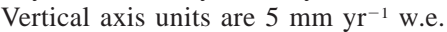

7) shows values less than $200 \mathrm{~mm} \mathrm{yr}^{-1}$ for nearly the whole of the region from $30^{\circ}-70^{\circ} \mathrm{E}$, with a large area of less than $100 \mathrm{~mm} \mathrm{yr}^{-1}$. This appears to support lower accumulation for this region; the Higham et al. accumulation contours end at the coastline, however, making the comparison ambiguous.

\section{c. Annual cycle}

In Fig. 11, average monthly values for the conterminous grounded ice and ice-shelf region defined by
GB85 are shown in comparison to other datasets for which monthly data are available. The ECMWF annual cycle is found to be unimodal for Antarctica with a maximum occurring in July. The NCEP-NCAR Reanalysis and the Jaeger climatology generally show similar patterns in the annual cycle, although NCEP-NCAR values are somewhat larger for December. The Legates and Willmott climatology shows a well-defined semiannual oscillation with the lowest values occurring in winter. The larger values suggest that the Legates and Willmott climatology is significantly influenced by 


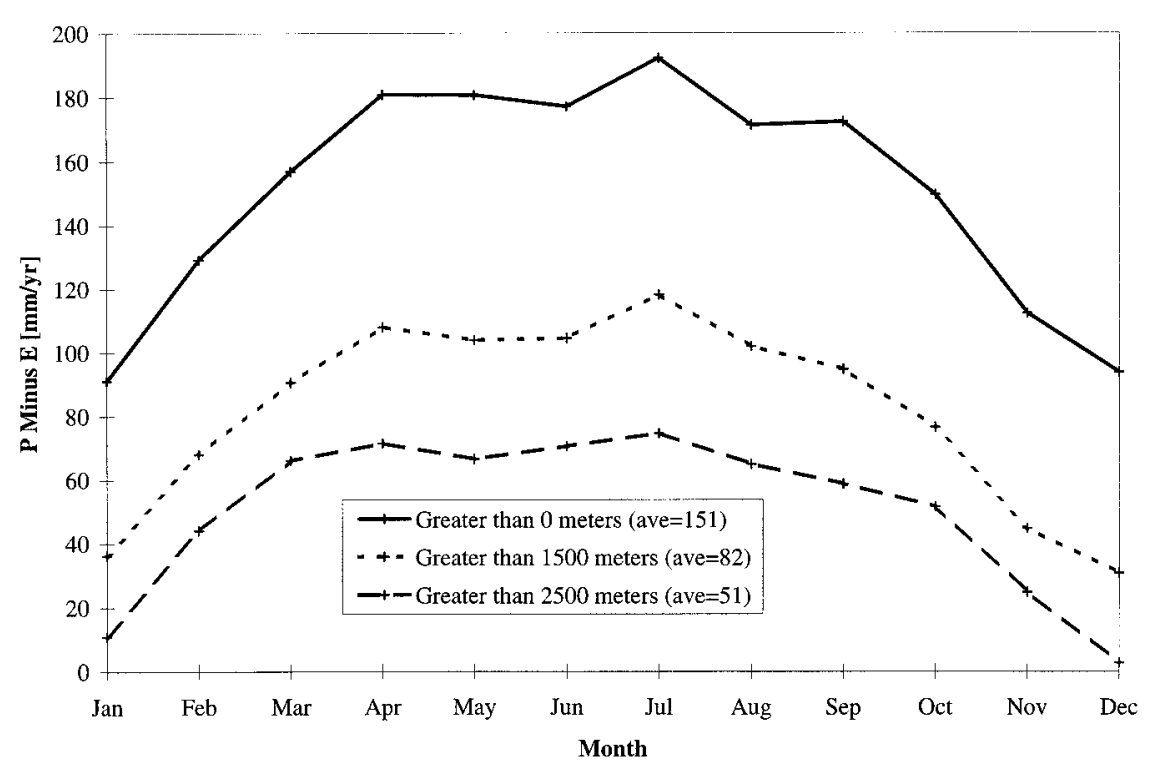

FIG. 13. Annual cycle of net precipitation derived from ECMWF for Antarctic continent above

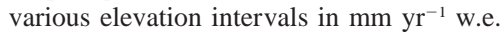

coastal stations. In Fig. 12, the ECMWF annual cycle is plotted for various point locations. A semiannual oscillation is most prominent for locations near the Antarctic Peninsula as well as offshore. For many coastal locations, particularly in east Antarctica, the annual cycle is not clearly defined. A unimodal annual cycle is found in coastal west Antarctica and the continental interior.

Figure 13 shows the annual cycle from ECMWF analyses for various elevations. Again, a single maximum is found for the three elevations examined. In particular, a well-defined annual cycle is found to occur for the high plateau region with larger values in winter and smaller values in summer. This is in disagreement with Budd et al. (1995), who show no cycle for higher elevations but is in agreement with observational data at Vostok (e.g., Bromwich 1988) and the South Pole (E.M. Thompson 1996, personal communication). Not shown, the Jaeger climatology has a similar unimodal cycle for elevations greater than $2500 \mathrm{~m}$, while the Legates and Willmott climatology again shows a bimodal cycle for high elevations. The cycles of these climatologies at high elevations are very similar to their corresponding cycles for the continent as a whole. The

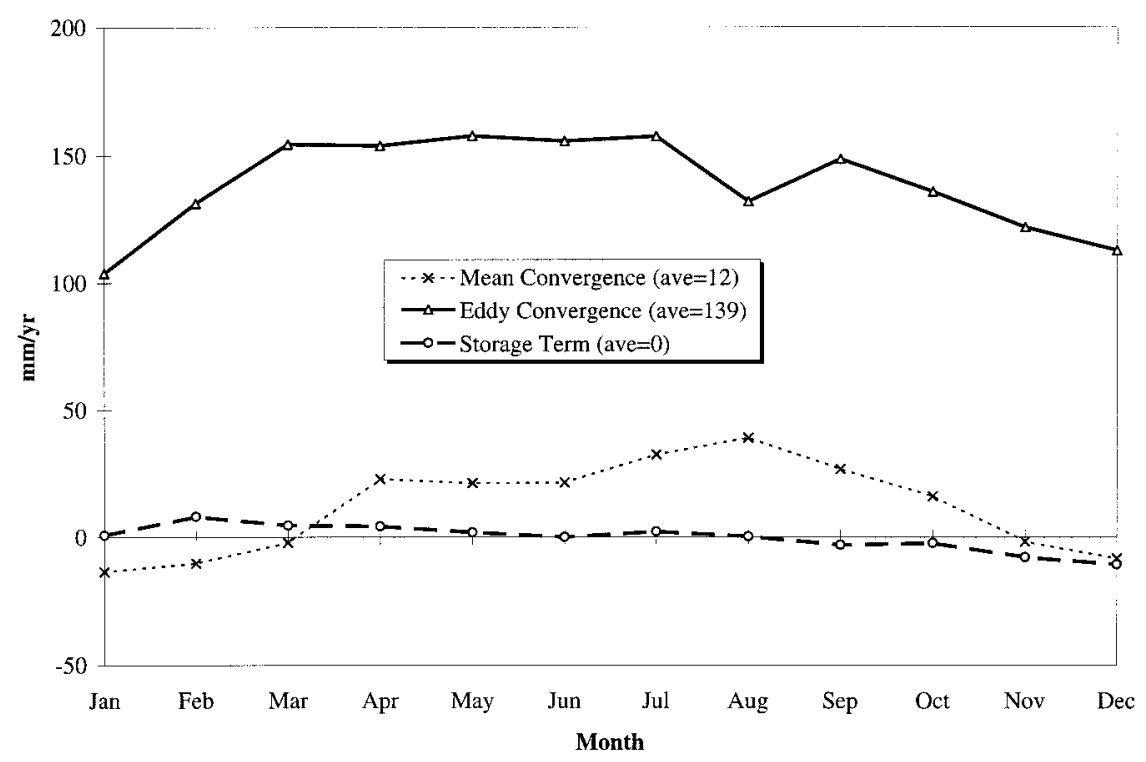

FIG. 14. Annual cycle of monthly mean, eddy, and storage values for Antarctic continent. 


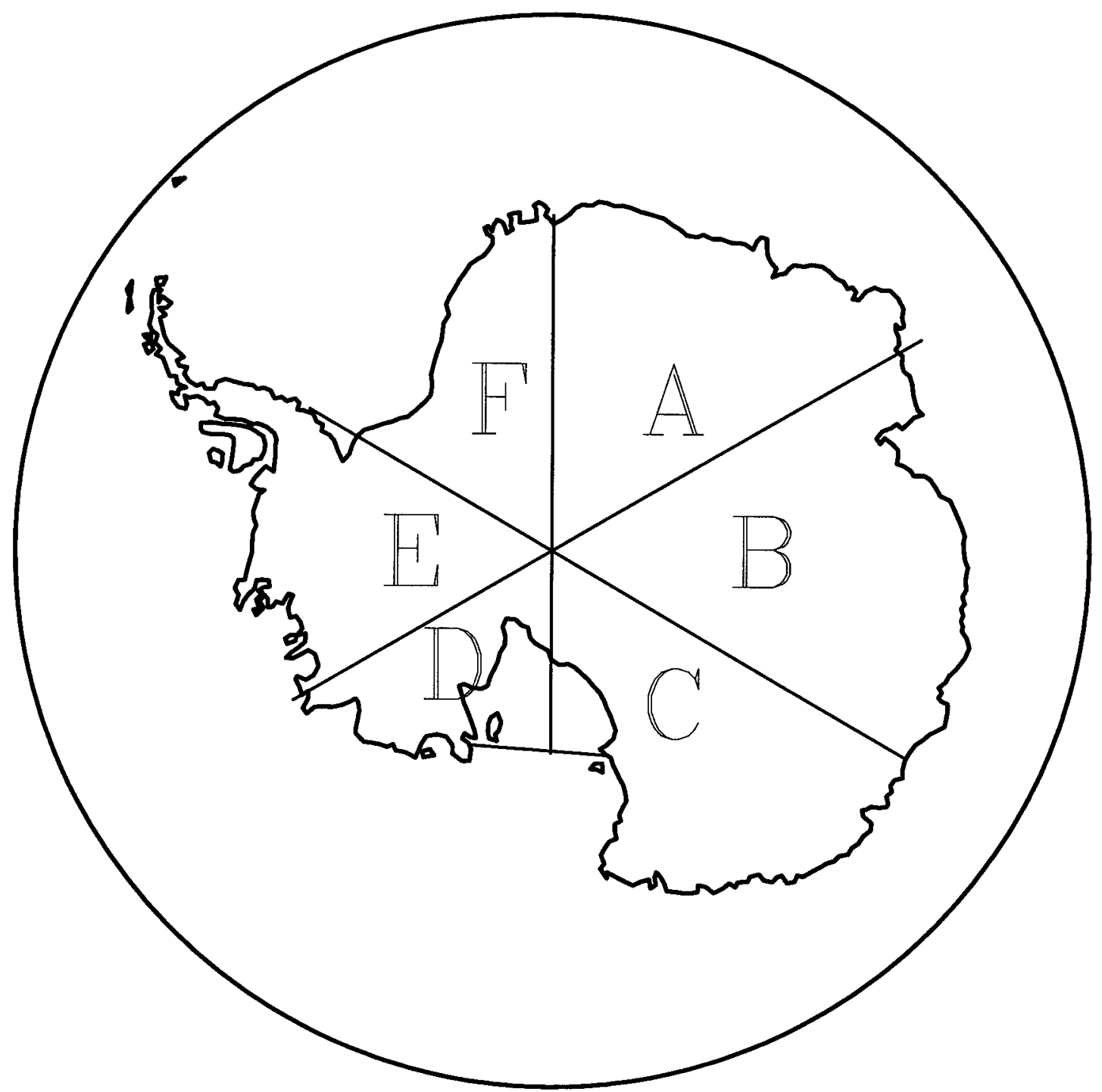

FIG. 15. Antarctic continent and adjacent ice shelves divided into six wedge-shaped sectors.

annual cycle for the NCEP-NCAR Reanalysis, however, is significantly different at high elevations. It depicts substantially higher values for December and January, with a weak unimodal cycle for the remaining months. This is reminiscent of the annual temperature cycle for the high plateau.

In Fig. 14, the annual cycle of mean, eddy, and storage components are shown for Antarctica. It may be seen that mean and eddy components display a cycle of lower values in summer. Mean convergence is significantly negative for the three summer months and accounts for only $8 \%$ of annual net precipitation for the continent. The storage term is found to be small on monthly timescales. To examine the regional variations of the mean and eddy convergence components, the continent is divided into six wedge-shaped sectors $\left(60^{\circ}\right.$ longitude wide) shown in Fig. 15. The annual cycles of the com- ponents of the moisture budget for the specified sectors are shown in Fig. 16. There is a general impression from this figure that eddy convergence experiences less seasonal variability than the mean convergence. Again, the mean convergence is a significant part of the total only for west Antarctic sectors D and E; significant mean divergence occurs for east Antarctic sector C. East Antarctic sectors $\mathrm{A}$ and $\mathrm{B}$ are generally characterized by low seasonal variability, with the mean component essentially negligible in comparison to the eddy contribution. A bimodal cycle is again found to be significant for the Antarctic Peninsula sector only (sector E). This is largely the result of mean convergence. Although the remaining sectors generally show a unimodal distribution, the timing of the maximum varies. Sector D clearly shows a maximum in May, while $\mathrm{C}$ shows a maximum in July. 



FIG. 16. As in Fig. 14 but for Antarctic regions defined in Fig. 15 in $\mathrm{mm} \mathrm{yr}^{-1}$ w.e. 


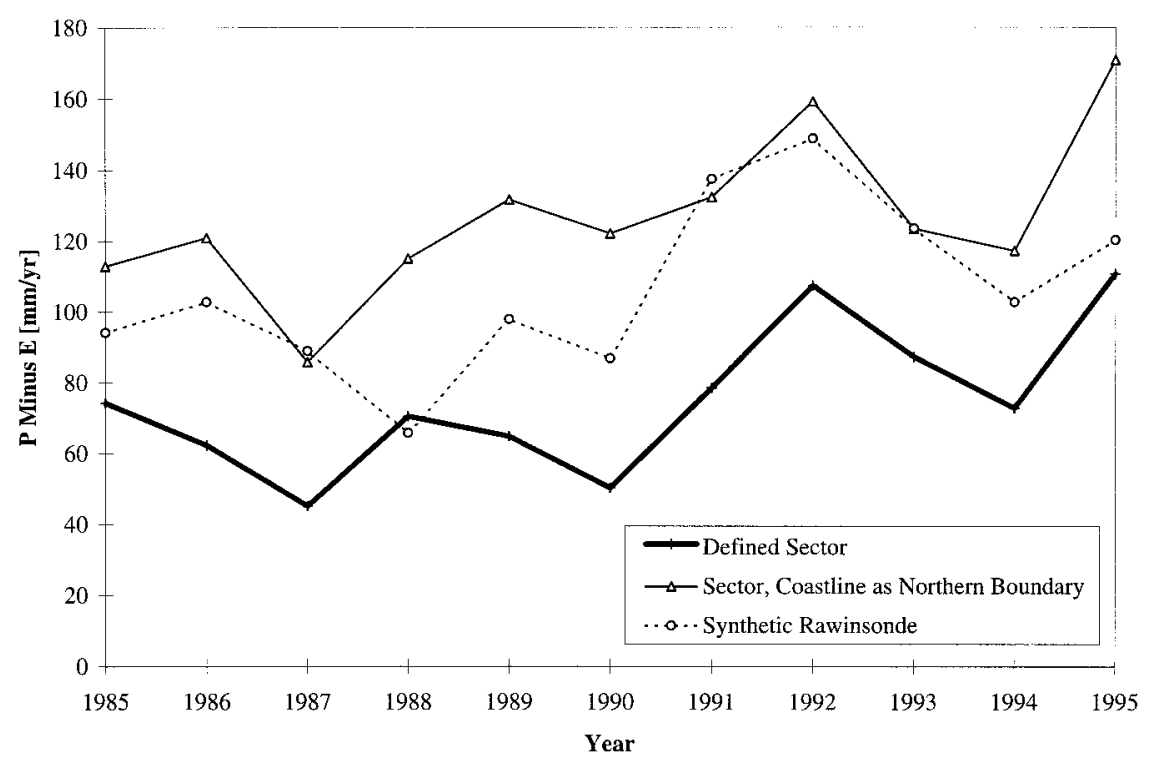

FIG. 17. Annual moisture transport convergence for the region $0^{\circ}-110^{\circ} \mathrm{E}$ using areal average of $78.2^{\circ} \mathrm{S}$ to the continental edge and using transport values as the pseudorawinsonde network.

\section{d. Case study of the east Antarctic rawinsonde network}

Bromwich et al. (1995) evaluated the ECMWF atmospheric moisture convergence in comparison to the rawinsonde network bounded by $0^{\circ}-110^{\circ} \mathrm{E}, 68.4^{\circ}-$ $78.2^{\circ} \mathrm{S}$. The convergence values were found to be in close agreement with rawinsonde data for the years 1988-89 as well as the long-term accumulation for the area determined from the available glaciological information. Connolley and King (1996) utilized the United Kingdom Meteorological Office Unified Climate Model to investigate the uncertainties in estimating sector accumulation from rawinsonde data. Connolley and King (1996) conclude that the rawinsonde method overestimates sector accumulation. Here, the moisture transports derived from the ECMWF analyses are utilized to reas- sess the previous conclusions of Bromwich et al. (1995). Two methods for computing the sector net precipitation are used. In the first method, gridpoint values located at station locations (Fig. 1) are used to produce synthetic rawinsondes from which the moisture convergence is determined. The zonal transports for Casey and SANAE stations are applied similar to Bromwich et al. (1995). A comparison of the rawinsonde transports to 1972 values tabulated by Bromwich (1979) indicates agreement to within $1-3 \mathrm{~kg} \mathrm{~m}^{-1} \mathrm{~s}^{-1}$ for each station. The exception to this is at SANAE, where the analyses show a southward transport in comparison to the station's 1972 northward flux. This is likely due to interannual variability, as there was good agreement with the rawinsonde data as shown by Bromwich et al. (1995). In the second method, the full-resolution ECMWF analyses are used

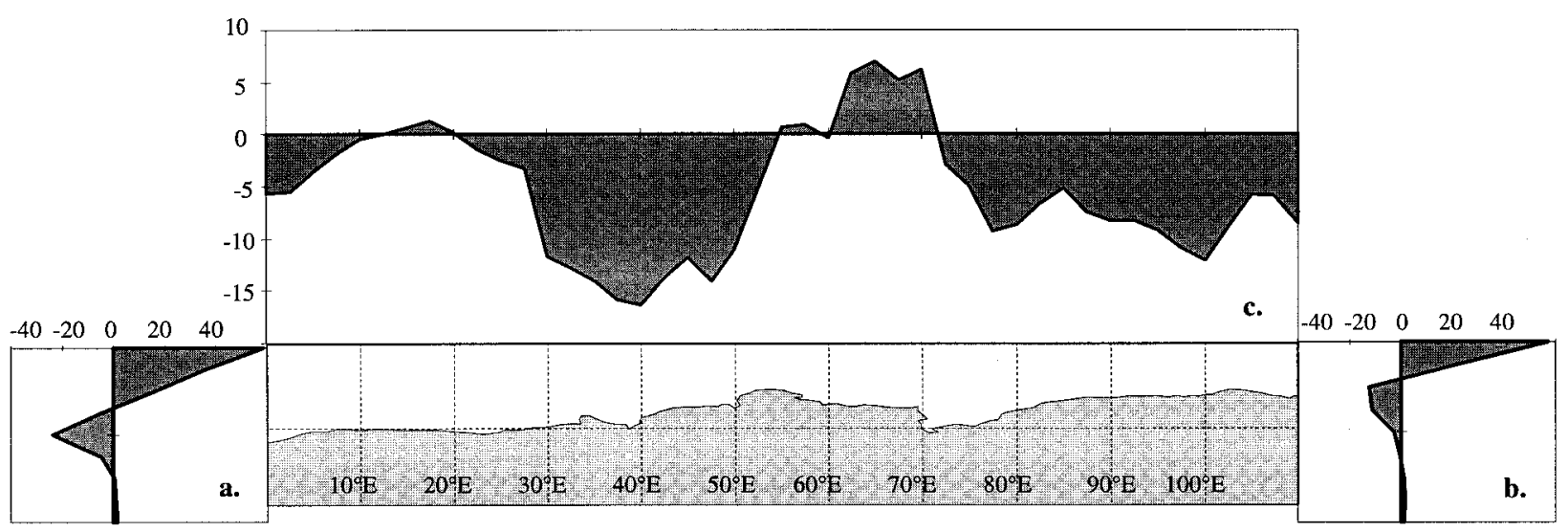

FIG. 18. Average ECMWF vertically integrated moisture transports crossing the (a) west, (b) east, and (c) north boundaries of the region bounded by $0^{\circ}-110^{\circ} \mathrm{E}, 78.2^{\circ} \mathrm{S}$ to the continental edge in $\mathrm{kg} \mathrm{m}^{-1} \mathrm{~s}^{-1}$. 


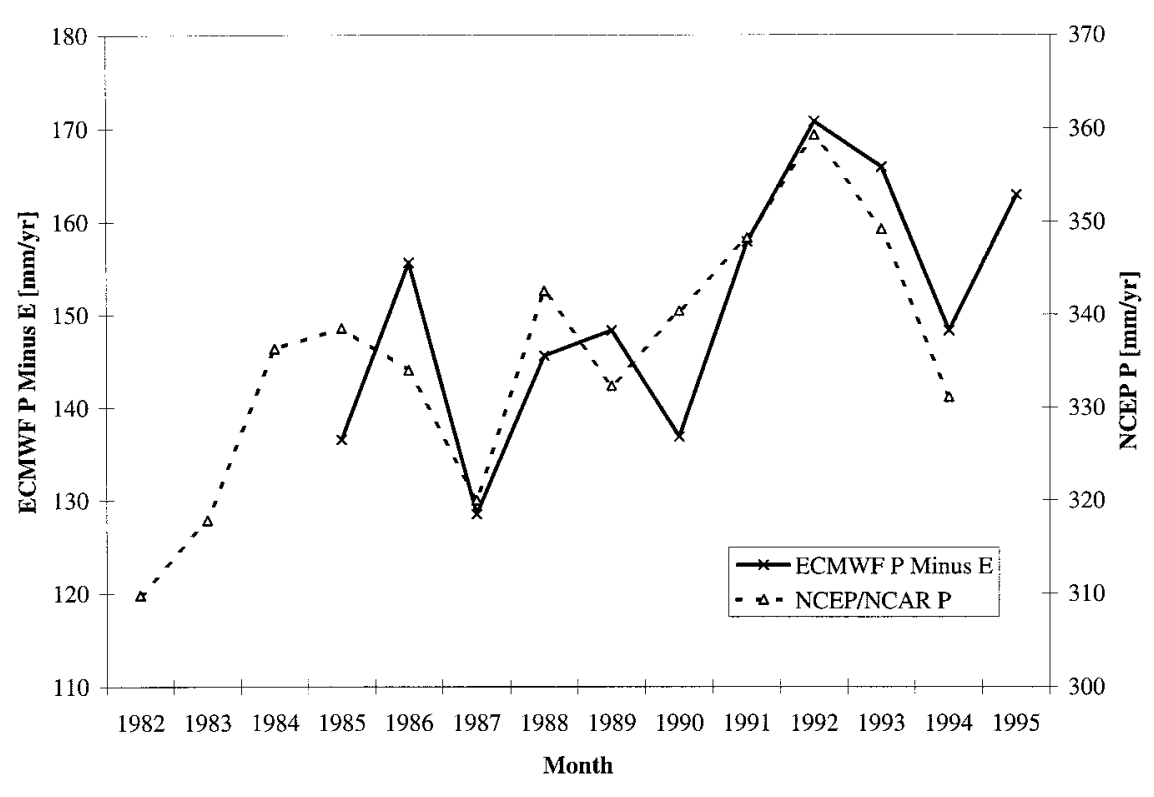

FIG. 19. Annual values of $P-E$ derived from ECMWF analyses and NCEP-NCAR Reanalysis precipitation for Antarctica in $\mathrm{mm} \mathrm{yr}^{-1}$ w.e. Note the different scales.

to determine the sector-averaged net precipitation, with the Antarctic coastline defining the northern boundary. This method accounts for the fact that the rawinsonde method was designed to approximate the continental area where accumulation data were collected (Bromwich 1979). Figure 17 shows a comparison of annual values for the two methods. The glaciological estimate for sector accumulation is $108 \mathrm{~mm} \mathrm{yr}^{-1}$; however, it is expected that this value has increased based on glaciological trends at other locations. From synthetic rawinsonde data, the average value is $106 \mathrm{~mm} \mathrm{yr}^{-1}$, compared with $127 \mathrm{~mm} \mathrm{yr}^{-1}$ for the sector using the coastline as the northern boundary. The correlation between the two methods is somewhat low $\left(r^{2}=0.42\right)$. It is apparent, however, that temporal lag occurs between events recorded in the rawinsonde method and the analyzed grid. There is reasonable agreement between the various methods for the annual cycle which show the largest values during winter months.

In Fig. 18, the averaged atmospheric moisture transports are shown along the $0^{\circ}$ and $110^{\circ} \mathrm{E}$ meridians which are used to compose the western and eastern boundaries and for the northern boundary defined by the coastline. The important caveat for the rawinsonde method is the resolution of transports in the vicinity of the Amery Ice Shelf. The analyses show strong outflow between Mawson and Davis stations, a feature not well captured by the trapezoidal integration between synthetic rawinsondes. The zonal transports for the sector eastern and western boundaries shown in Fig. 18 are found not to balance. This is in disagreement with the assumption used by Connolley and King (1996); this is not surprising given that zonal transports at Casey and SANAE stations are not equal.
In summary, the rawinsonde method is found to reproduce the trends and large-scale variability of the sector as shown in Fig. 17. For the comparison between the synthetic rawinsonde data and the areal average, the values are within $20 \%$. A principal objection to the rawinsonde method has been that the observed humidity data are systematically in error due to the very cold conditions. It has been suggested that the coastal location of the stations, where relatively warm conditions prevail, reduces uncertainty in the rawinsonde data (e.g., Bromwich et al. 1995). This is implied by the close agreement between the glaciological value and the rawinsonde method shown here.

\section{e. Interannual variability}

Figure 19 shows annual net precipitation values for the ECMWF analyses in comparison to NCEP-NCAR Reanalysis precipitation. Globally, the ECMWF analyses have been shown to produce increasing values of net precipitation as a result of adjustments to the assimilation model and, in particular, to the convective cloud parameterization (Trenberth and Guillemot 1995); longterm trends must therefore be viewed with some caution. Additionally, Cullather et al. (1996) show Antarctic trends to be strongly influenced by the El NiñoSouthern Oscillation phenomenon. The close agreement between the two methods, however, implies a validation of the significant trend of +2.0 to $+2.5 \mathrm{~mm} \mathrm{yr}^{-1}$; this upward trend is in agreement with other studies (e.g., Thompson et al. 1996; Bromwich and Robasky 1993; Morgan et al. 1991). Figure 20 shows annual values and convergence decomposition for the sectors defined in Fig. 15. It may be seen that the mean component is 

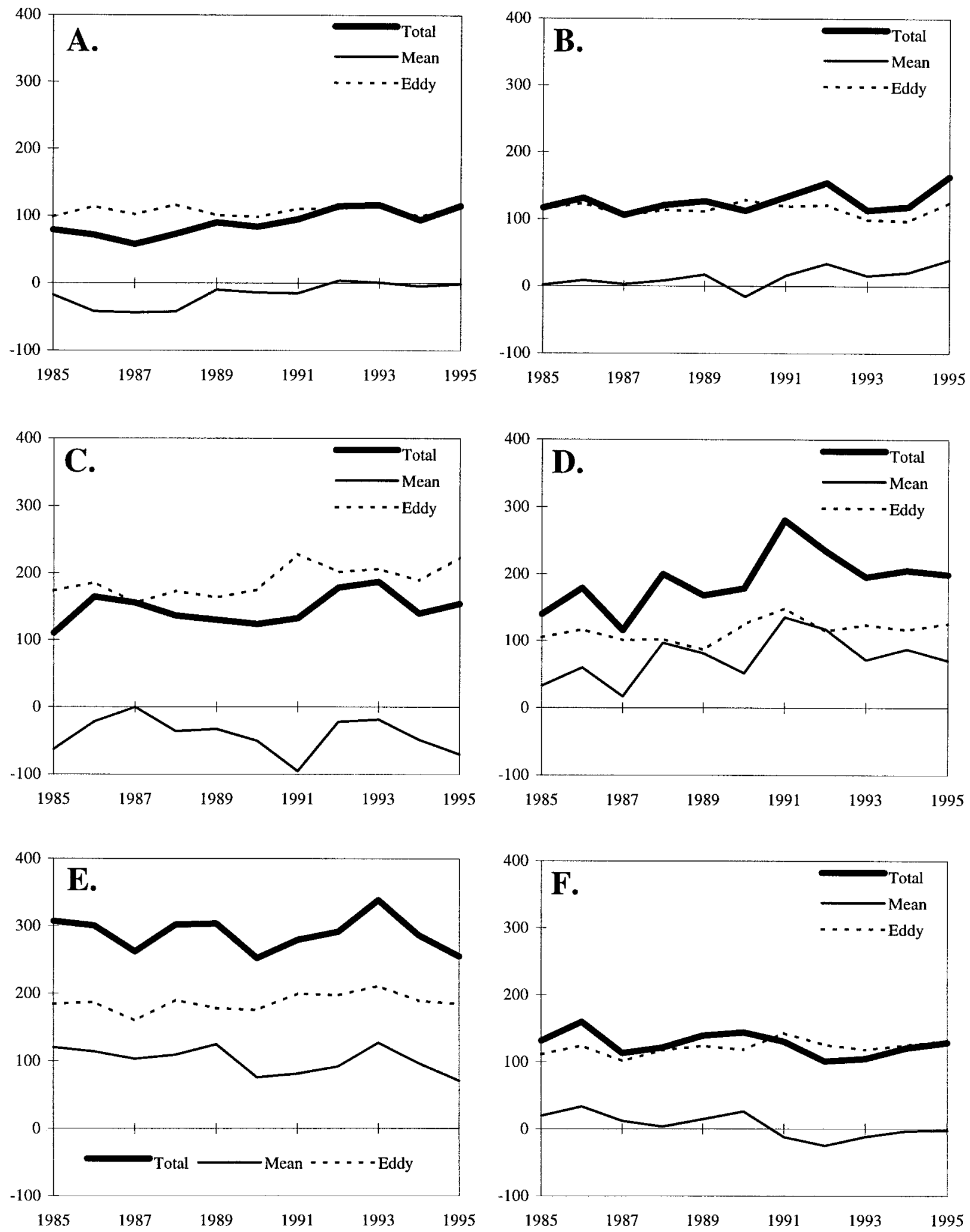

FIG. 20. Annual values of total, mean, and eddy moisture convergence from ECMWF analyses for sectors defined in Fig. 15 in $\mathrm{mm}^{-1} \mathrm{w}^{-1}$.e. 


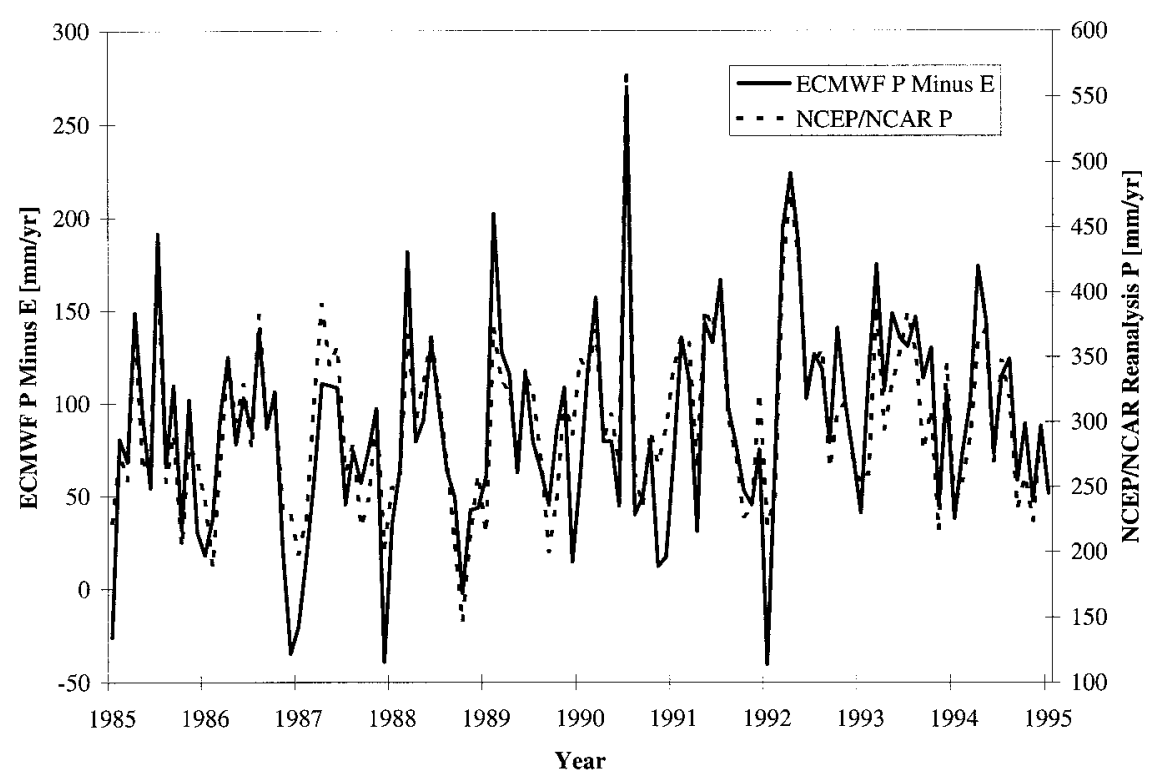

FIG. 21. Monthly values of ECMWF $P-E$ and NCEP-NCAR Reanalysis precipitation for

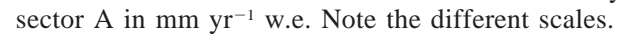

responsible for upward trends in east Antarctic sectors $\mathrm{A}$ and $\mathrm{B}$, as well as west Antarctic sector D. The rising eddy component is also significant for sector C. Consistent with Bromwich et al., the largest interannual variability is found to occur in the South Pacific sector D, which is largely the result of the mean component. A particularly striking result is the comparison of the NCEP-NCAR Reanalysis with sector A (Fig. 21). Although agreement ranges from fair to poor for other regions, it may be seen that monthly variability in ECMWF net precipitation is reproduced by the NCEPNCAR Reanalysis $\left(r^{2}=0.8\right)$. The close agreement for this sector is likely related to the relatively dense upperair network for this region, which may mitigate differences in the assimilation models and the reanalysis PAOBS error. The agreement between methods for sector A in particular and Antarctica in general argues that further refinement of the analyses may introduce some additional degree of reliability.

Mechanisms for producing large-scale precipitation are of interest. In Fig. 22, the 10 highest ECMWF $P-$ $E$ months are composited and subtracted from an 11-yr average climatology. The climatology is produced by weighting each average month by the frequency that it appears in the list of the 10 highest $P-E$ months. The largest values on the difference map occur in east Antarctica near Porpoise Bay $\left(\sim 130^{\circ} \mathrm{E}\right)$ and along the Amundsen-Bellingshausen coast of west Antarctica. The locations of these values correspond to the largest differences with the glaciological composite of GB85 as shown in Fig. 6b. The contribution of eddy convergence to values in these locations suggests that cyclonic activity and storm-track variability are contributors to enhanced net precipitation events. To assess this, the analyses twice daily mean sea level pressure (MSLP) fields have been filtered (Duchon 1979) for synoptic activity from 2.5 to 6 days $(n=60)$. The rms of the filtered MSLP data is composited for the 10 months of interest and plotted in Fig. 23a. The ECMWF climatology for similar months is shown in Fig. 23b. The 10 months of interest range from April to October. An enhanced storm track into the eastern Ross Ice Shelf is clearly present in both the 10-month composite and the climatology. For the 10 highest net precipitation months, this track is strengthened slightly, although Fig. 22 indicates that this does not have a significant impact on $P-E$ for the area. Of importance is the large synoptic variability extending from the Southern Ocean into Wilkes Land in east Antarctica. In Fig. 24a, the average $500-\mathrm{hPa}$ geopotential height field is composited for the 10-months of interest, while the ECMWF climatology for similar months is shown in Fig. 24b. The composite plot shows a well-defined ridge extending into Wilkes Land. Although this feature is also present in the climatology, it is not as strong. The presence of the Wilkes Land ridge has previously been shown to be a mode for enhanced precipitation in west Antarctica on ENSO timescales (Cullather et al. 1996). This analysis, however, shows that the strength of the ridge also affects the Southern Ocean storm track around east Antarctica, probably by steering cyclones into Wilkes Land.

\section{Discussion}

In this paper, similarities and discrepancies between the ECMWF atmospheric moisture budget, glaciological observations, and various other atmospheric methods are identified. An adequate appraisal of the spatial vari- 


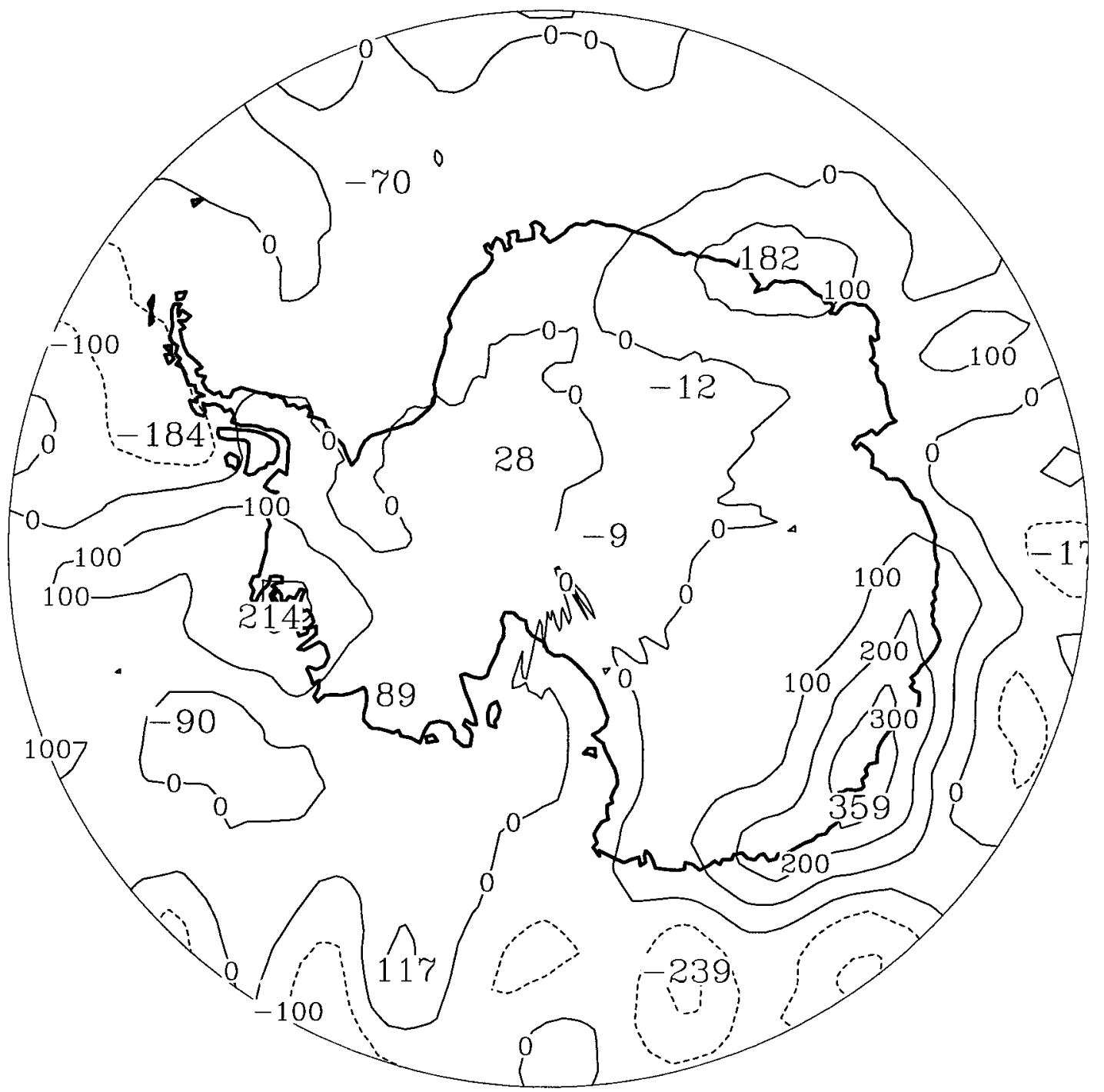

FIG. 22. ECMWF net precipitation for the 10 highest months (April 1992, August 1992, June 1995, April 1995, July 1986, July 1985, July 1992, June 1992, October 1986, June 1987) minus the 11-yr climatology in $\mathrm{mm} \mathrm{yr}^{-1}$ w.e.

ability in Antarctic precipitation requires the resolution of these differences. This necessitates concurrent data from all methods to eliminate uncertainty produced by asynchronous comparisons. While reliable atmospheric numerical analyses have only been produced from the time of the First GARP Global Experiment (1979), a large fraction of Antarctic glaciological observations predate this period. This study, as well as point glaciological measurements, strongly imply that Antarctic accumulation values have increased from the time of these previous measurements. This is a strong motivating factor for the ITASE project to obtain a contemporary and time-varying accumulation depiction from glaciological methods.

Perhaps the most troubling discrepancy is the spatial representation of $P-E$ over the Ross Ice Shelf that is in substantial disagreement with glaciological observations. This is possibly due to the detailed topography in this region and the difficulties that numerical weather prediction models, utilized in producing analyses, have in the presence of steep orography. Gibbs errors associated with the Transantarctic Mountains extend quite far onto the Ross Ice Shelf (Cullather et al. 1996, see their Fig. 2). These errors are further exacerbated by the use of a deficient elevation database (Genthon and Braun 1995). The treatment of topography appears to be the limiting factor for this method. A primary goal of the Antarctic First Regional Observing Study of the Troposphere (Turner et al. 1996) is to provide additional information on how well the numerical weather prediction models reproduce observed conditions; this should lead to improvements in the analyses' representation of 


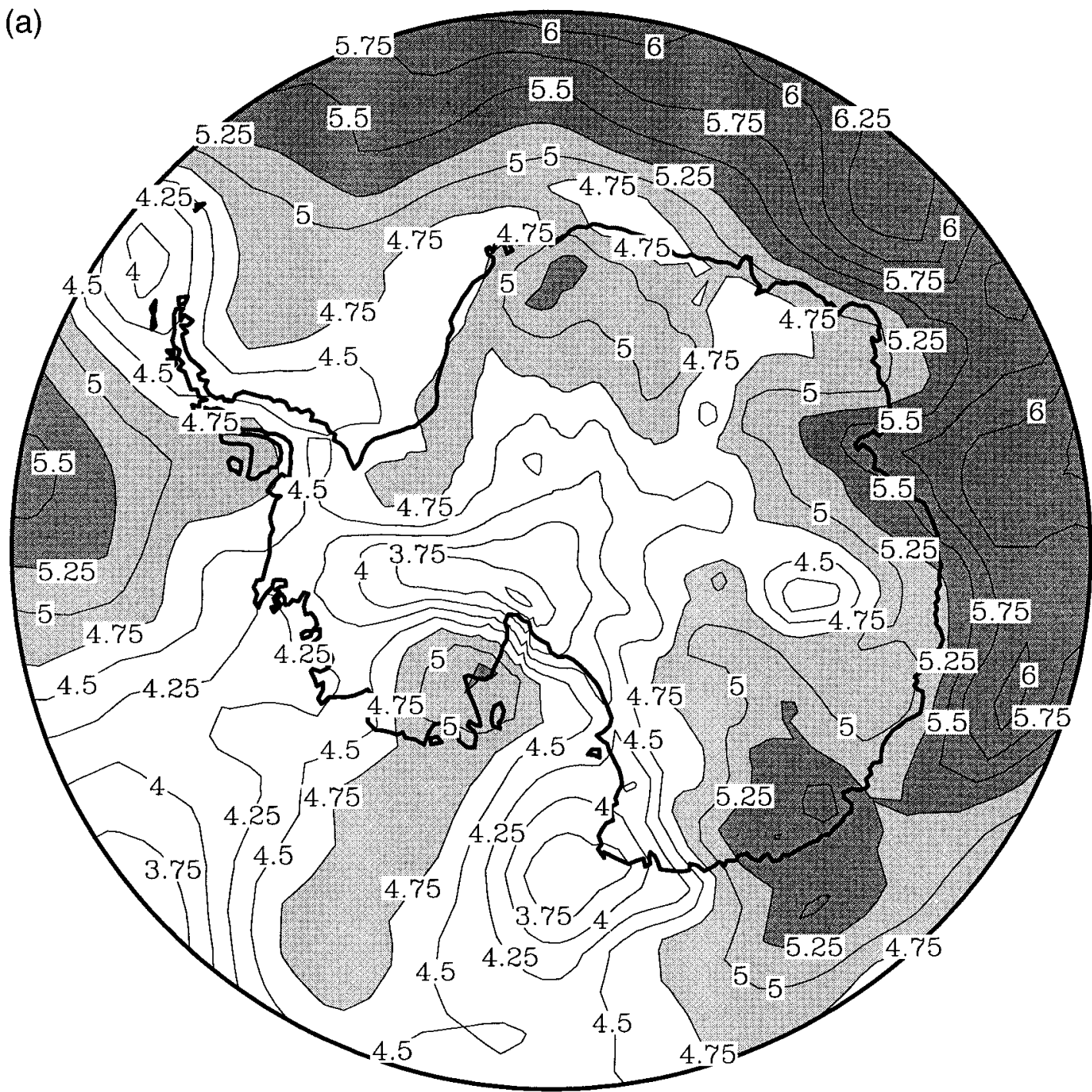

FIG. 23. Average mean sea level pressure synoptic variability (a) for the 10 highest net precipitation months and (b) 11 -yr climatology in $\mathrm{hPa}$. Note that the physical meaning of sea level isobars becomes ambiguous in the presence of high elevations in the interior of the continent.

the atmospheric hydrologic cycle in high southern latitudes.

An analysis of annual cycles derived from the ECMWF moisture budget for various locations, as well as sector-averaged regions, indicates a bimodal annual cycle in net precipitation for the Antarctic Peninsula region, consistent with van Loon (1972) and Turner et al. (1997). Although the semiannual oscillation may significantly influence the net precipitation annual cycle for other locations, it is not clearly discernible; there appear to be other regional effects that confound this signal. Over the high plateau, there is consistency between the ECMWF atmospheric moisture budget and glaciological observations in depicting a unimodal annual cycle with larger values in winter.
An important discrepancy with GB85 is the $P-E$ maximum associated with the storm track entering Porpoise Bay. Given the scarcity of glaciological data for the area and the agreement with Reid and Budd (1995, see Fig. 9a) this appears to be a real feature, and this area has been previously highlighted as an area of cyclonic variability (Jacobs 1992; Morgan et al. 1991).

Despite large regional differences between studies, the general agreement on the broad features of Antarctic precipitation indicates that a threshold may have been reached where the assessment of the smaller terms of (1) is essential to resolving discrepancies. In particular, evaporation/sublimation is known to be nonnegligible for Antarctica (Stearns and Weidner 1993), and methods for describing the spatial and temporal variability will 


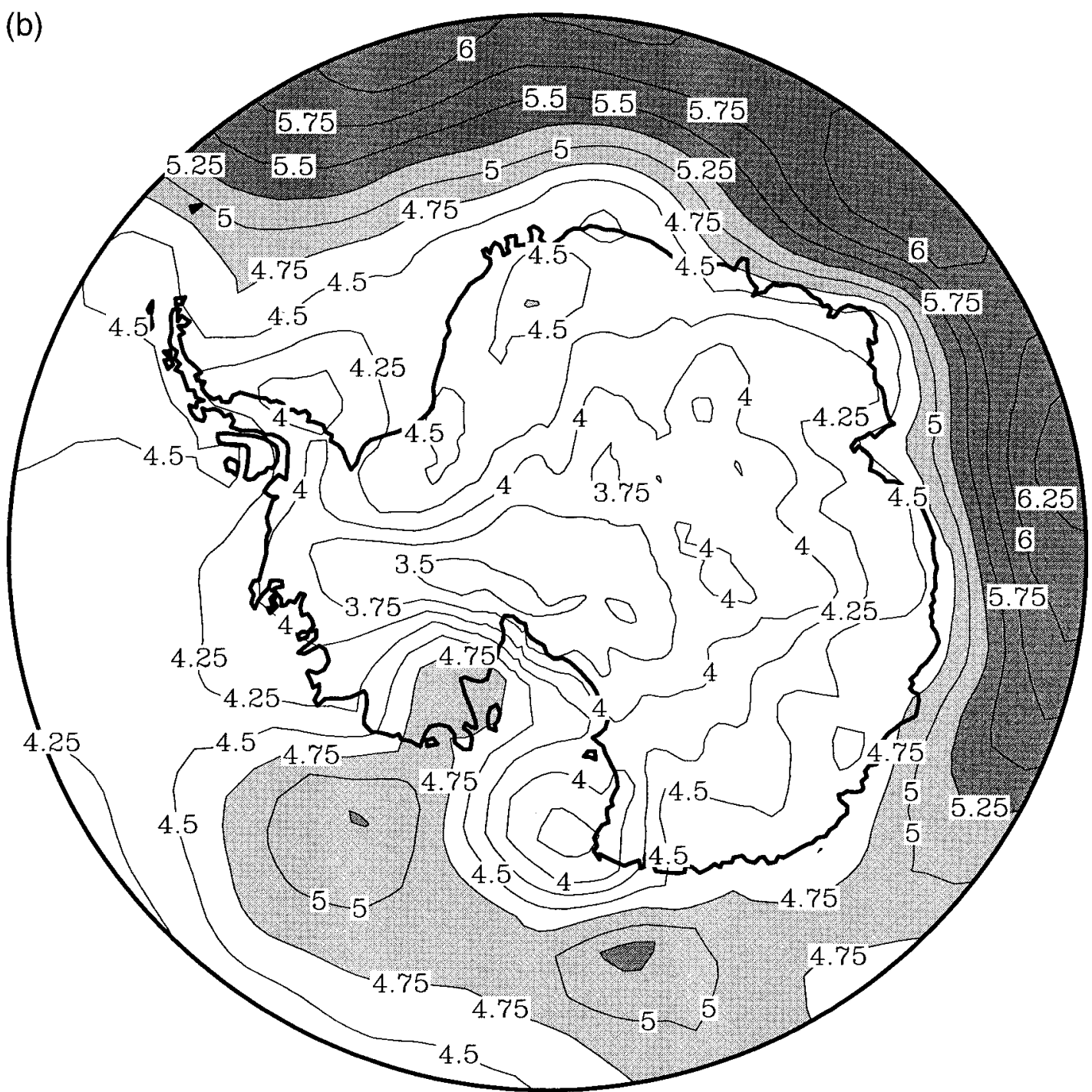

FIG. 23. (Continued)

require additional development. Studies of the point and areal-averaged drift snow loss have a substantial history in the Antarctic (e.g., Lister 1960; Budd et al. 1966; Takahashi et al. 1984, 1988; Giovinetto et al. 1992); these approaches have not been applied to atmospheric numerical analyses. This uncertainty in the smaller terms of (1) outlined here is in agreement with the conclusions of Budd et al. (1995).

Acknowledgments. ECMWF analyses were obtained from NCAR. This research was sponsored by the National Aeronautics and Space Administration under Grants NAGW 3677 to the second author and W-18795 to the third author.

\section{REFERENCES}

Allison, I., 1979: The mass budget of the Lambert drainage basin, Antarctica. J. Glaciol., 22, 223-235.
Arpe, K., and H. Cattle, 1993: A comparison of surface stress and precipitation fields in short-range forecasts over the Antarctic region. J. Geophys. Res., 98, 13 035-13044.

Bromwich, D. H., 1979: Precipitation and accumulation estimates for East Antarctica, derived from rawinsonde information. Ph.D. thesis, University of Wisconsin-Madison, $142 \mathrm{pp}$. [Available from Dept. of Atmospheric and Oceanic Sciences, University of Wisconsin-Madison, 1225 W. Dayton Street, Madison, WI 53706-1695.]

— , 1988: Snowfall in high southern latitudes. Rev. Geophys., 26, 149-168.

, 1990: Estimates of Antarctic precipitation. Nature, 343, 627629 .

, and F. M. Robasky, 1993: Recent precipitation trends over the polar ice sheets. Meteor. Atmos. Phys., 51, 259-274.

- - R. I. Cullather, and M. L. Van Woert, 1995: The atmospheric hydrologic cycle over the Southern Ocean and Antarctica from operational numerical analyses. Mon. Wea. Rev., 123, $3518-3538$.

Bryazgin, N. N., 1982: Atmospheric precipiation in Antarctica. Polar Geogr. Geol., 6, 210-218. 


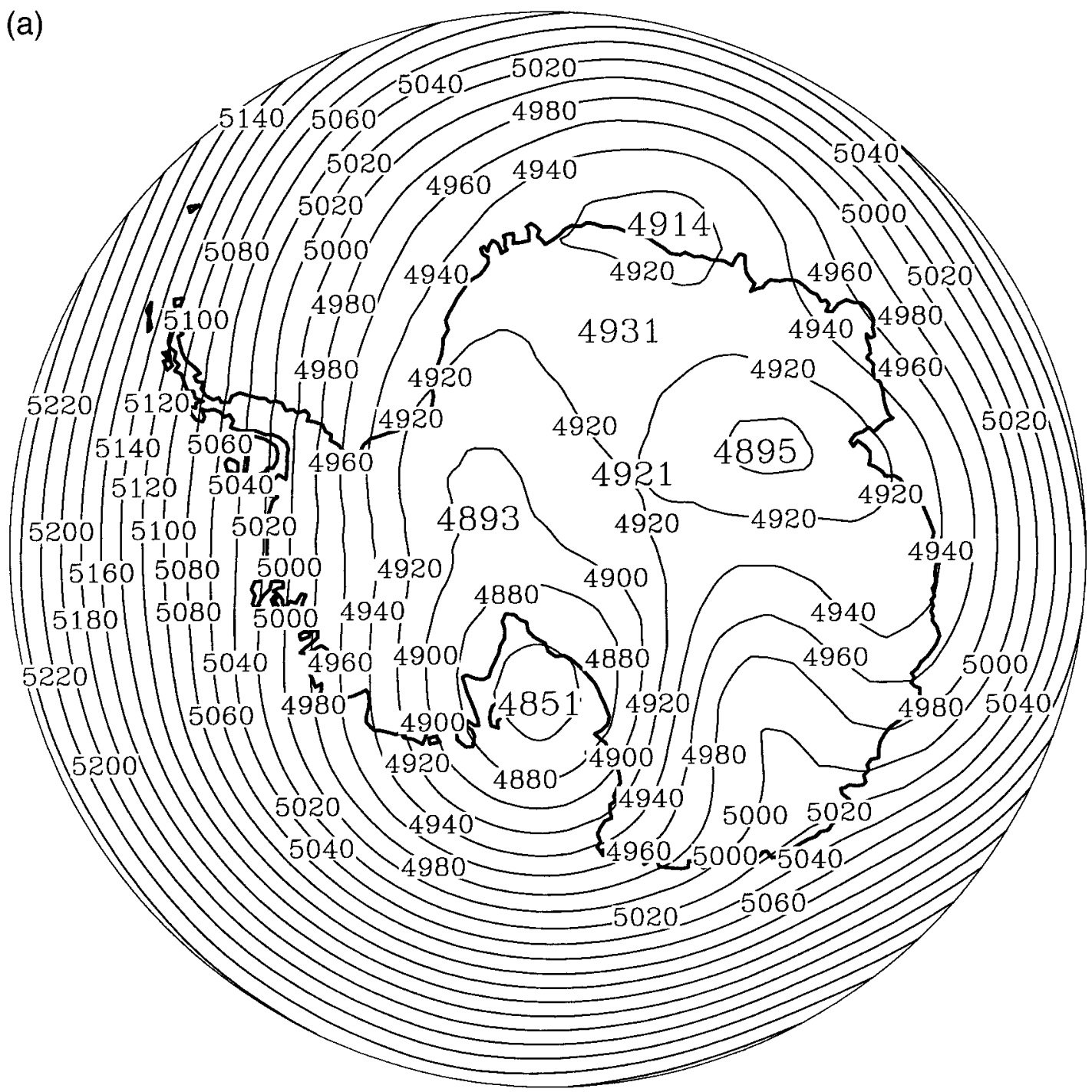

FIG. 24. Average 500-hPa geopotential height (a) for the 10 highest net precipitation months and (b) 11-yr climatology for similar months in gpm.

Budd, W. F., W. R. J. Dingle, and U. Radok, 1966: The Byrd Snow Drift Project: Outline and basic results. Studies in Antarctic Meteorology, M. J. Rubin, Ed., Antarc. Res. Series, Vol. 9, Amer. Geophys. Union, 71-134.

_, R. A. Reid, and L. J. Minty, 1995: Antarctic moisture flux and net accumulation from global atmospheric analyses. Ann. Glaciol., 21, 149-156.

Cameron, R. L., 1964: Snow accumulation. Physical Characteristics of the Antarctic Ice Sheet, V. C. Bushnell, Ed., Antarctic Map Folio Series, Amer. Geogr. Soc., Folio 2, 2.

Connolley, W. M., and J. C. King, 1993: Atmospheric water-vapour transport to Antarctica inferred from radiosonde data. Quart. J. Roy. Meteor. Soc., 119, 325-342.

_ , and - 1996: A modeling and observational study of East Antarctic surface mass balance. J. Geophys. Res., 101, 13351343.

Cullather, R. I., D. H. Bromwich, and M. L. Van Woert, 1996: Interannual variability in Antarctic precipitation related to El Niño-Southern Oscillation. J. Geophys. Res., 101, 1910919118.
- - - and R. W. Grumbine, 1997: Validation of operational numerical analyses in Antarctic latitudes. J. Geophys. Res., 102, $13761-13784$.

Dodd, J. P., and I. N. James, 1996: Diagnosing the global hydrological cycle from routine atmospheric analyses. Quart. J. Roy. Meteor. Soc., 122, 1475-1499.

Drewry, D. J., 1983: The surface of the Antarctic ice sheet. Antarctica: Glaciological and Geophysical Folio, Scott Polar Research Institute, Sheet 2.

Duchon, C. E., 1979: Lanczos filtering in one and two dimensions. J. Appl. Meteor., 18, 1016-1022.

Endlich, R. M., 1967: An iterative method for altering the kinematic properties of wind fields. J. Appl. Meteor., 6, 837-844.

Enomoto, H., 1991: Fluctuations of snow accumulation in the Antarctic and sea level pressure in the Southern Hemisphere in the last 100 years. Climate Change, 18, 67-87.

Fortuin, J. P. F., and J. Oerlemans, 1990: Parameterization of the annual surface temperature and mass balance of Antarctica. Ann. Glaciol., 14, 78-84.

Frolich, R. M., 1992: The surface mass balance of the Antarctic 


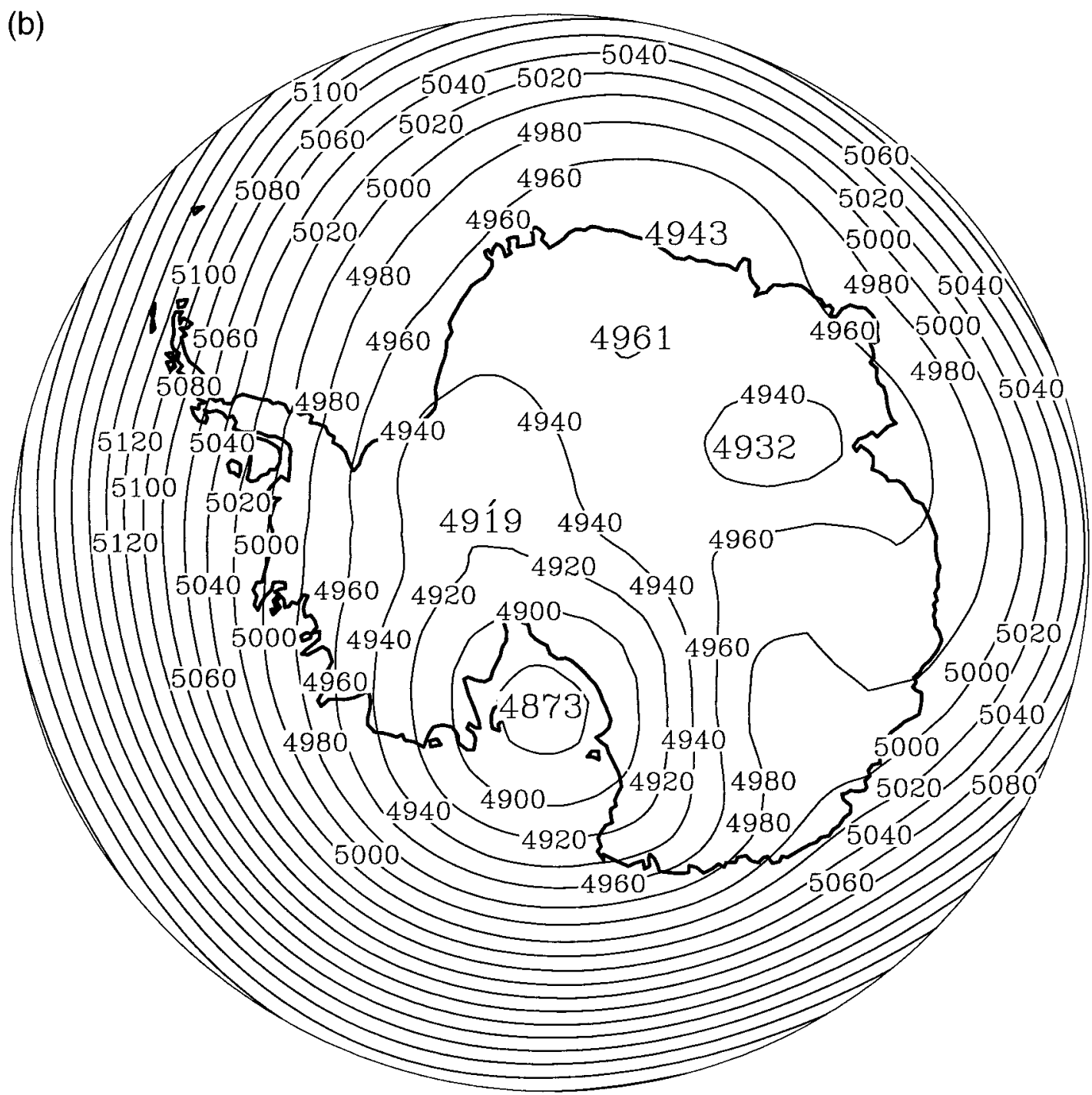

FIG. 24. (Continued)

Peninsula ice sheet. The Contribution of the Antarctic Peninsula to Sea Level Rise, E. M. Morris, Ed., British Antarctic Survey, 3-9.

Genthon, C., and A. Braun, 1995: ECMWF analyses and predictions of the surface climate of Greenland and Antarctica. J. Climate, 8, 2324-2332.

Giovinetto, M. B., and C. R. Bentley, 1985: Surface balance in ice drainage systems of Antarctica. Antarct. J. U.S., 20, 6-13.

— , and C. Bull, 1987: Summary and analysis of surface mass balance compilations for Antarctica, 1960-1985. Byrd Polar Res. Center Rep. 1, 90 pp. [Available from Goldthwait Polar Library, Byrd Polar Research Center, 1090 Carmack Road, Columbus, OH 43210-1002.]

- D. H. Bromwich, and G. Wendler, 1992: Atmospheric net transport of water vapor and latent heat across $70^{\circ}$ S. J. Geophys. Res., 97, 917-930.

Goodwin, I. D., 1995: On the Antarctic contribution to Holocene sealevel. Ph.D. thesis, University of Tasmania, 315 pp. [Available from Institute of Antarctic and Southern Ocean Studies, GPO Box 252-77, Hobart, TAS 7001, Australia.]

Higham, M., M. Craven, A. Ruddell, and I. Allison, 1997: Snow accumulation distribution in the interior of the Lambert Glacier Basin, Antarctica. Ann. Glaciol., 25, 413-417.

Hines, K. M., D. H. Bromwich, and R. I. Cullather, 1997: Evaluating moist physics for Antarctic mesoscale simulations. Ann. Glaciol., 25, 277-286.

Howarth, D. A., 1983: Seasonal variations in the vertically integrated water vapor transport fields over the Southern Hemisphere. Mon. Wea. Rev., 111, 1259-1272.

_ 1986: An analysis of the water vapor flux divergence field over the Southern Hemisphere. Ann. Assoc. Amer. Geogr., 76, 190 207.

_, and J. N. Rayner, 1986: Estimates of sources and sinks of atmospheric moisture in the Southern Hemisphere. Extended Abstracts, Second Int. Conf. on Southern Hemisphere Meteorology, Wellington, New Zealand, Amer. Meteor. Soc., 163-166.

Hurrell, J. W., 1990: Maintenance of short-term subtropical wind maxima in the Southern Hemisphere: Observational and modelling study. Ph.D. thesis, Purdue University, 107 pp. [Available from Dept. of Earth and Atmospheric Sciences, Purdue University, 1397 Civil Engineering Building, West Lafayette, IN $47907-$ 1397.] 
Jacobs, S. S., 1992: Is the Antarctic ice sheet growing? Nature, 360, 29-33.

- , H. H. Helmer, C. S. M. Doake, A. Jenkins, and R. M. Frolich, 1992: Melting of ice shelves and the mass balance of Antarctica. J. Glaciol., 38, 375-387.

Jaeger, L., 1976: Monaskarten des Niederschlags fur die ganze Erde. Rep. of the German Weather Service 139, Vol. 18, Offenbach, Germany, 33 pp. and plates.

Kalnay, E., and Coauthors, 1996: The NCEP-NCAR 40-year reanalysis project. Bull. Amer. Meteor. Soc., 77, 437-471.

Kattenberg, A., and Coauthors, 1995: Climate models-Projections of future climate. Climate Change 1995, The Science of Climate Change: Contribution of Working Group 1 to the Second Assessment Report of the Intergovernmental Panel on Climate Change, J. T. Houghton, L. G. Meira Filho, B. A. Callandar, N. Harris, A. Kattenberg, and K. Maskell, Eds., Cambridge University Press, 285-357.

Legates, D. R., and C. J. Willmott, 1990: Mean seasonal and spatial variability in gauge corrected, global precipitation. Int. J. Climatol., 10, 111-127.

Lettau, B., 1969: The transport of moisture into the Antarctic interior. Tellus, 21, 331-340.

Lister, H., 1960: Glaciology, Part 1: Solid precipitation and drift snow, Transantarctic Expedition, 1955-1958. Scient. Rep. 5, 51 pp. [Available from Goldthwait Polar Library, Byrd Polar Research Center, 1090 Carmack Road, Columbus, OH 43210-1002.]

Masuda, K., 1990: Atmospheric heat and water budgets of polar regions: Analysis of FGGE data. Proc. NIPR Symp. Polar Meteor. Glaciol., 3, 79-88.

Mayewski, P. A., Ed., 1996: Science and Implementation Plan for the U.S. Contribution to the International Trans-Antarctic Scientific Expedition (ITASE). Research Rep., University of New Hampshire, 62 pp. [Available from Climate Change Research Center, EOS-Morse Hall, University of New Hampshire, Durham, NH 03824-3525.]

McIntyre, N., 1985: A re-assessment of the mass balance of the Lambert Glacier drainage basin, Antarctica. J. Glaciol., 31, 3438.

Mechoso, C. R., 1980: The atmospheric circulation around Antarctica: Linear stability and finite-amplitude interactions with migrating cyclones. J. Atmos. Sci., 37, 2209-2233.

Morgan, V. I., I. D. Goodwin, D. M. Etheridge, and C. W. Wookey, 1991: Evidence from Antarctic ice cores for recent increases in snow accumulation. Nature, 354, 58-60.

Ohmura, A., M. Wild, and L. Bengtsson, 1996: A possible change in mass balance of Greenland and Antarctic ice sheets in the coming century. J. Climate, 9, 2124-2135.

Oki, T., K. Musiake, K. Masuda, and H. Matsuyama, 1993: Global runoff estimation by atmospheric water balance using ECMWF data set. Macroscale Modelling of the Hydrosphere, IAHS Press, 163-171.

Parish, T. R., and D. H. Bromwich, 1991: Continental-scale simulation of the Antarctic katabatic wind regime. J. Climate, 4, 136-146.

Peixoto, J. P., and A. H. Oort, 1983: The atmospheric branch of the hydrological cycle and climate. Variations in the Global Water Budget, A. Street-Perrott, M. Beran, and P. Ratcliffe, Eds., D. Reidel, 5-65.

Reid, P. A., and W. F. Budd, 1995: Calculation of Antarctic surface ice mass accumulation through atmospheric parameters. Abstracts, APOC-AMOS Conf., Lorne, Australia, Austr. Meteor. Ocean. Soc., 104. [Available from Administrative Officer, Australian Meteorological and Oceanographic Society, P.O. Box 654E, Melbourne, VIC 3001, Australia.]

Schwerdtfeger, W., 1984: Weather and Climate of the Antarctic. Developments in Atmospheric Science. Vol. 15. Elsevier, 261 pp.

Seaman, R., P. Steinle, and T. Hart, 1993: The impact of manually derived Southern Hemisphere sea level pressure data upon forecasts from a global model. Wea. Forecasting, 8, 363-368.
Starr, V. P., J. P. Peixoto, and R. McKean, 1969: Pole-to-pole moisture conditions for the IGY. Pure Appl. Geophys., 15, 300-331.

Stearns, C. R., and G. A. Weidner, 1993: Sensible and latent heat flux estimates in Antarctica. Antarctic Meteorology and Climatology: Studies Based on Automatic Weather Stations, Antarctic Research Series, Vol. 61, Amer. Geophys. Union, 109-138.

Stephens, J. J., 1967: On convergence of the Endlich iteration method. J. Appl. Meteor., 6, 845-847.

Swarztrauber, P. N., 1974: The direct solution of the discrete Poisson equation on the surface of a sphere. J. Comput. Phys., 15, 46-54.

Takahashi, S., H. Ohmae, M. Ishikawa, T. Katsushima, and F. Nishic, 1984: Observation of snow drift flux at Mizuho station, East Antarctica, 1982. Mem. Natl. Inst. Polar Res., Spec. Issue, 34, 113-121.

_, R. Naruse, M. Nakawo, and S. Mae, 1988: A bare ice field in East Queen Maud Land, Antarctica, caused by horizontal divergence of drifting snow. Ann. Glaciol., 11, 156-160.

Thomas, R. H., D. R. MacAyeal, D. H. Eilers, and D. R. Gaylord, 1984: Glaciological studies on the Ross Ice Shelf, Antarctica, 1973-1978. The Ross Ice Shelf: Glaciology and Geophysics, Antarct. Res. Series, Vol. 42, Amer. Geophys. Union, 21-53,

Thompson, E.-M., L. G. Thompson, J. F. Paskievitch, M. Pourchet, A. J. Gow, M. E. Davis, and J. Kleinman, 1995: Recent increase in South Pole snow accumulation. Ann. Glaciol., 21, 131-138.

Trenberth, K. E., 1991: Climate diagnostics from global analyses: Conservation of mass in ECMWF analyses. J. Climate, 4, 707-722.

_ 1992: Global analyses from ECMWF and atlas of 1000 to 10 mb circulation statistics. NCAR Tech. Note NCAR/TN$373+$ STR, 191 pp., plus 24 fiche.

, and A. Solomon, 1994: The global heat balance: Heat transports in the atmosphere and ocean. Climate Dyn., 10, 107-134.

_ and C. J. Guillemot, 1995: Evaluation of the global atmospheric moisture budget as seen from analyses. J. Climate, 8, 22552272.

_ J. W. Hurrell, and A. Solomon, 1995: Conservation of mass in three dimensions in global analyses. J. Climate, 8, 692-708.

Turner, J., and Coauthors, 1996: The Antarctic First Regional Observing Study of the Troposphere (FROST) project. Bull. Amer. Meteor. Soc., 77, 2007-2032.

_, S. R. Colwell, and S. Harangozo, 1997: Variability of precipitation over the coastal western Antarctic Peninsula from synoptic observations. J. Geophys. Res., 102, 13 999-14007.

Tzeng, R.-Y., D. H. Bromwich, T. R. Parish, and B. Chen, 1994: NCAR CCM2 simulation of the modern Antarctic climate. $J$. Geophys. Res., 99, 23 131-23 148.

van Loon, H., 1967: The half-yearly oscillations in middle and high southern latitudes and the coreless winter. J. Atmos. Sci., 24, 472-486.

_ 1972: Cloudiness and precipitation in the Southern Hemisphere. Meteorology of the Southern Hemisphere, Meteor. Monogr., No. 35, Amer. Meteor. Soc., 101-111.

Walsh, K., and J. L. McGregor, 1996: Simulations of Antarctic climate using a limited area model. J. Geophys. Res., 101, $19093-$ 19108

Warrick, R. A., C. Le Provost, M. F. Meier, J. Oerlemans, and P. L. Woodworth, 1995: Changes in sea level. Climate Change 1995, The Science of Climate Change: Contribution of Working Group 1 to the Second Assessment Report of the Intergovernmental Panel on Climate Change, J. T. Houghton, L. G. Meira Filho, B. A. Callandar, N. Harris, A. Kattenberg, and K. Maskell, Eds., Cambridge University Press, 359-405.

Yamazaki, K., 1992: Moisture budget in the Antarctic atmosphere. Proc. NIPR Symp. Polar Meteor. Glaciol., 6, 36-45.

_ 1994: Moisture budget in the Antarctic atmosphere. Snow and Ice Covers: Interactions with the Atmosphere and Ecosystems, H. G. Jones, T. D. Davies, A. Ohmura, and E. M. Morris, Eds., IAHS Press, 61-67.

Zwally, H. J., and M. B. Giovinetto, 1995: Accumulation in Antarctica and Greenland derived from passive-microwave data: A comparison with contoured compilations. Ann. Glaciol., 21, 123130. 